\title{
Revisitando os Chões de Alpompé com técnicas de detecção remota: novas evidências sobre os sistemas defensivos Romano-Republicanos
}

\author{
Revisiting Chões de Alpompé with remote \\ sensing techniques: new evidence on \\ Romano-Republican defensive system
}

\author{
JOÃO FONTE \\ Department of Archaeology \\ University of Exeter \\ j.fonte3@exeter.ac.uk \\ https://orcid.org/0000-0003-0367-0598 \\ CARLOS PEREIRA \\ UNIARQ - Centro de Arqueologia da Universidade de Lisboa \\ Faculdade de Letras da Universidade de Lisboa \\ carlos_samuel_pereira@hotmail.com \\ https://orcid.org/0000-0002-4116-3602
}

\author{
JOÃO PIMENTA \\ CEAX (Centro de Estudos Arqueológicos Vila Franca de Xira) \\ joao.marques@cm-vfxira.pt \\ https://orcid.org/oooo-0001-5149-5566
}

\author{
ANA MARGARIDA ARRUDA \\ UNIARQ - Centro de Arqueologia da Universidade de Lisboa \\ Faculdade de Letras da Universidade de Lisboa \\ a.m.arruda@letras.ulisboa.pt
}

https://orcid.org/0000-0002-7446-1104

\begin{abstract}
Resumo
O planalto dos Chões de Alpompé, em Santarém, foi, pelo menos desde os anos 50 do século XX, alvo de numerosos trabalhos de prospecção e de campanhas de escavação e acompanhamento de actividades agrícolas. Tais trabalhos proporcionaram a recolha de inúmeros materiais arqueológicos, muitos dos quais já publicados, que deixam antever uma relevante ocupação humana durante a Idade do Ferro e época Romano-Republicana. Todavia, a definição dos seus sistemas defensivos foi sempre difícil, situação que resulta em grande parte da densa cobertura florestal que o cobre. A recente disponibilidade, para esta zona do baixo Vale do Tejo, de dados de laser aéreo, bem como a sua combinação com fotografia aérea histórica, permitiu identificar e mapear novas estruturas arqueológicas que autorizam uma visão renovada sobre as estruturas do sítio. Esta leitura tem também em consideração os recentes dados obtidos nas intervenções arqueológicas de escavação e acompanhamento decorridas entre 2015 e 2018, que permitiram esclarecer algumas questões relevantes sobre estes sistemas defensivos.
\end{abstract}

Palavras-chave: Chões de Alpompé, Idade do Ferro, Romano, LiDAR, fotografia aérea

\section{Abstract}

The Chões de Alpompé plateau in Santarém has been the target of numerous archaeological surveys and excavations since the 1950's. Such works provided the collection of numerous archaeological materials, many of which have already been published, which suggest a relevant human occupation during the Iron Age and Romano-Republican periods. However, the definition of its defensive systems has always been difficult, a situation that results largely from the dense forest cover that affects it. The recent availability, for this area of the lower Tagus Valley, of airborne laser scanning data, as well as its combination with historical aerial photography, has made it possible to identify and map new archaeological structures that allow a renewed interpretation of the site's structures. This proposal also takes into account recent data obtained from archaeological surveys and excavations that took place between 2015 and 2018, which allowed us to clarify some relevant questions about these defensive systems.

Key words: Chões de Alpompé, Iron Age, Roman, LiDAR, aerial photography 


\section{Chões de Alpompé: leituras históricas e arqueológicas}

O sítio arqueológico de Chões de Alpompé situa-se no interior de uma propriedade privada, a Quinta de Alpompé, na união de freguesias de São Vicente do Paul e Vale de Figueira, concelho e distrito de Santarém. Desenvolve-se de forma estratégica, ocupando um vasto planalto, com mais de 20 hectares e 96 metros de altitude máxima, implantado sobre o rio Alviela, a escassa distância da sua confluência com o rio Tejo (figuras I e 2).

O reconhecimento da sua relevância científica e patrimonial verificou-se nos anos cinquenta do século passado, quando Bairrão Oleiro e Amorim Girão classificaram o planalto dos Chões como acampamento militar romano (Girão e Oleiro, 1953). A descrição era clara: «Acampamento de terraço fluvial ou, melhor, de uma série de terraços sobrepostos que deram o nome ao local - os Chóes - a muralha levantava-se, toda ela, no rebordo do terraço superior e não precisava exteriormente de qualquer outra obra de defesa.» (Girão e Oleiro, I953: 77). A partir deste trabalho, o sítio foi sistematicamente reconhecido e citado como um dos mais importantes sítios arqueológicos portugueses, concretamente no que se refere ao processo de conquista romana no território da Ulterior. Recentemente, dois de nós (J.P. e A.M.A.) tiveram a oportunidade de sintetizar a já longa história dos trabalhos arqueológicos que ocorreram no local e de refletir sobre as distintas leituras acerca das suas ocupações (Pimenta e Arruda, 20I4), não parecendo pertinente voltar agora a repetir, de novo, os argumentos e as hipóteses então levantadas.

Parece, contudo, relevante sublinhar que a grande extensão, a quantidade e a qualidade do espólio recuperado, assim como a visibilidade de um sistema defensivo em talude ainda bem preservado, contribuíram para a notoriedade que o sítio alcançou no panorama arqueológico nacional. Porém, até ao ano de 2015 nunca aí haviam sido realizadas escavações arqueológicas, correspondendo os dados existentes a trabalhos de prospecção, a maioria de contornos, no mínimo, pouco claros (Arruda et alii, 2018).

Deve também assinalar-se que o debate em torno de Chões de Alpompé se prendeu, quase sempre,com questões de Geografia Histórica, uma vez que, desde cedo, se pretendeu fazer corresponder o sítio à «cidade» que o cônsul Décimo Júnio Bruto terá usado para estacionar o seu exército (Girão e Oleiro, 1953: 80), tendo Móron servido como base para a campanha do general ao Noroeste peninsular (Estrabão, III, 3.I) (Deserto e Pereira, 2016: 59-6o). Outros autores sugeriram, posteriormente, distintas hipóteses $\mathrm{pa}-$ ra a localização do núcleo urbano mencionado pelo geógrafo de Amásia (Alarcão, 1983: 36; 2002: 37-38; Mantas, 1986: 590-592; Kalb e Hock, I988).

A identificação dos Chões de Alpompé com Morón teve por base três argumentos: o geográfico, uma vez que a distância relativamente ao mar é consentânea com a referência de Estrabão (Deserto e Pereira, 2016: 59-60); o tipológico, que assenta na ampla dimensão do sítio e nas fortificações de terra, em talude, consensualmente atribuídas à arquitetura militar romana; e o arqueológico, que tem em consideração o rico e diversificado espólio que foi recolhido nos distintos trabalhos no terreno, quase todos, como referimos, de prospecção.

Relativamente a este último aspeto, destacam-se os conjuntos cerâmicos, sobressaindo o extenso conjunto de ânforas recolhido e publicado por diversos autores em distintos enquadramentos temporais e institucionais (para a extensa lista de trabalhos ver síntese em Pimenta e Arruda, 20I4).

Importa aqui reter, em linhas gerais, o conjunto de ânforas, visto que parece atestar um quadro de abastecimento de cariz institucional normalmente associado aos exércitos consulares. Os contentores vinícolas da Península Itálica dominam de forma clara, em particular os oriundos da costa Tirrénica, representados por ânforas Greco-Itálicas tardias ou de transição e de tipo Dressel r. Surgem igualmente, ainda que em menor número, ânforas da costa Adriática, também Greco-Itálicas tardias, de Brindisi, e Lamboglia 2. Paralelamente aos produtos itálicos, verifica-se uma estreita conexão com o mundo da área "púnica» do Sul peninsular, em particular com a baía gaditana e com a região líbio-tunisina. Os preparados piscícolas da área do estreito de Gibraltar estão bem representados, tendo sido transportados nas ânforas dos Tipos T-9.I.I.I. (CCNN) e T-7.4·3.3. (Manã C2b) de Ramon Torres (1995). 


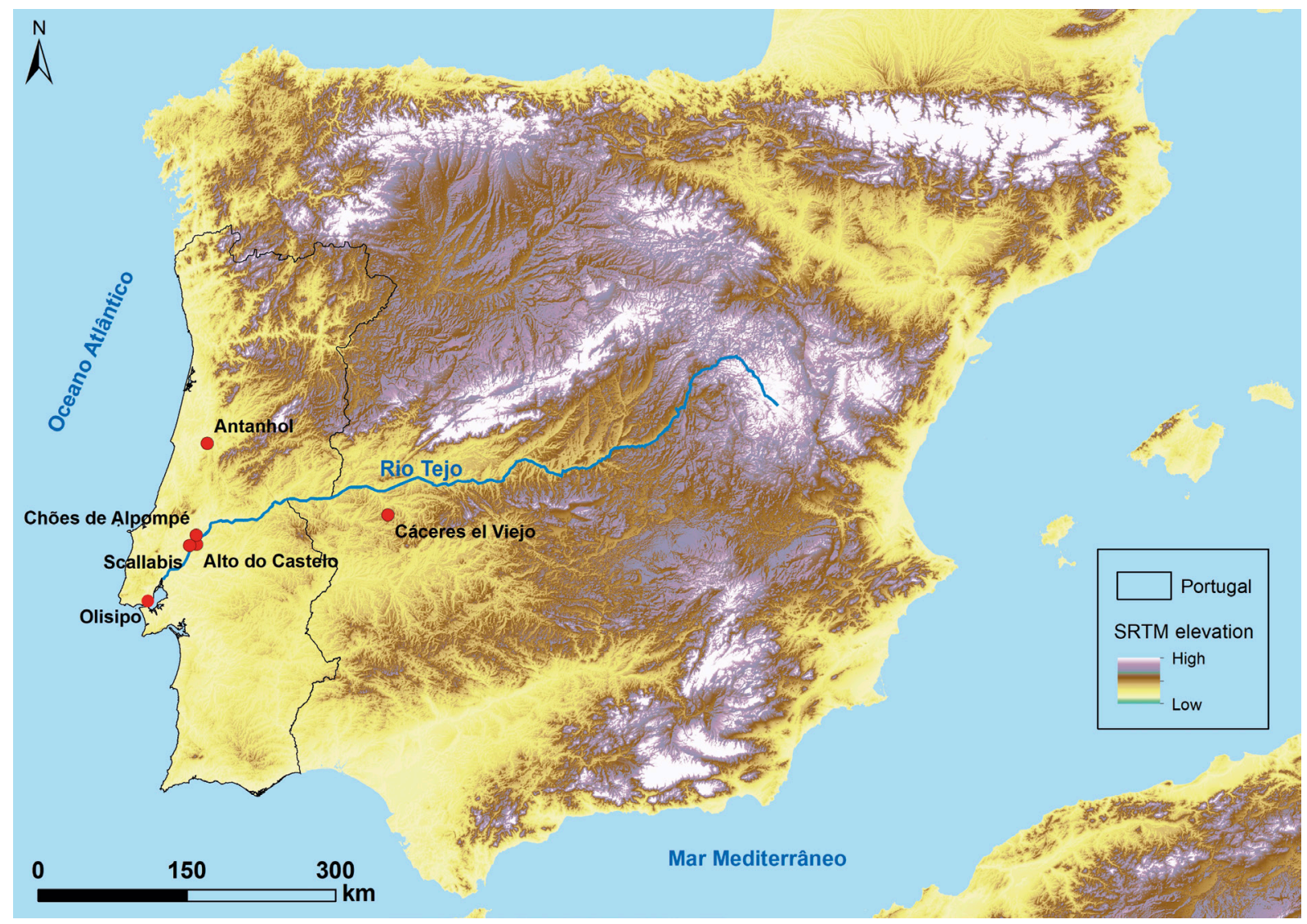

Figura 1. Localização no contexto da Península Ibérica de Chões de Alpompé e dos principais sítios arqueológicos mencionados no texto

Figure 1. Location in the Iberian Peninsula of Chões de Alpompé and the main archaeological sites mentioned in the text

A importação de azeite da área líbio-tunisina foi concretizada em numerosas ânforas oleícolas, denominadas Tripolitanas Antigas. Apesar de carecer do devido enquadramento contextual e estratigráfico, o conjunto de ânforas reflete o típico quadro de importações da segunda metade do século II e I a. C., destacando-se os materiais de perfil antigo que remetem para os contextos bem definidos de Lisboa (Pimenta, 2005) e de Valência (Ribera Lacomba, 1998; 2002), ambos datados do terceiro quartel do século ir a. C. e, assim, compatíveis com a campanha de Bruto.

A escassez de cerâmicas finas poderia justificar-se pelo facto de se tratar, maioritariamente, de materiais recolhidos em prospecção. Não obstante, esta mesma escassez foi igualmente verificada na intervenção de 2015 (Arruda et alii, 20I8), pelo que se deverá ter também em consideração a própria natureza da ocupação e a sua funcionalidade. A presença de vasos de verniz negro itálico, de tipo Campaniense A e B, de paredes finas itálicas e de lucernas foi, contudo, documentada quer nos trabalhos de prospeç̧ão quer nos de escavação.

Igualmente significativa é a presença de um amplo conjunto de metais, nomeadamente numismas, militaria, tendo-se também registado vestígios de transformação do metal. O conjunto numismático conhecido é numeroso, composto por um pequeno tesouro de 20 denários e por $\mathrm{I}_{3} \mathrm{I}$ unidades correspondentes a perdas isoladas (Ruivo, 1999). Destas, I28 são anteriores a 80 a. C. e três pertencem ao reinado de Augusto. Tendo em consideração estes elementos, José Ruivo sugeriu que o local teria sido abandonado no âmbito dos conflitos Sertorianos (Ruivo, I999: I06).

Os artefactos relacionados com a transformação do metal encontram-se bem atestados por vestígios de natureza diversa: escórias, lingotes e peças em processo de fabrico e em diferentes tipos de metal, nomeadamente ferro, chumbo, liga de cobre, 


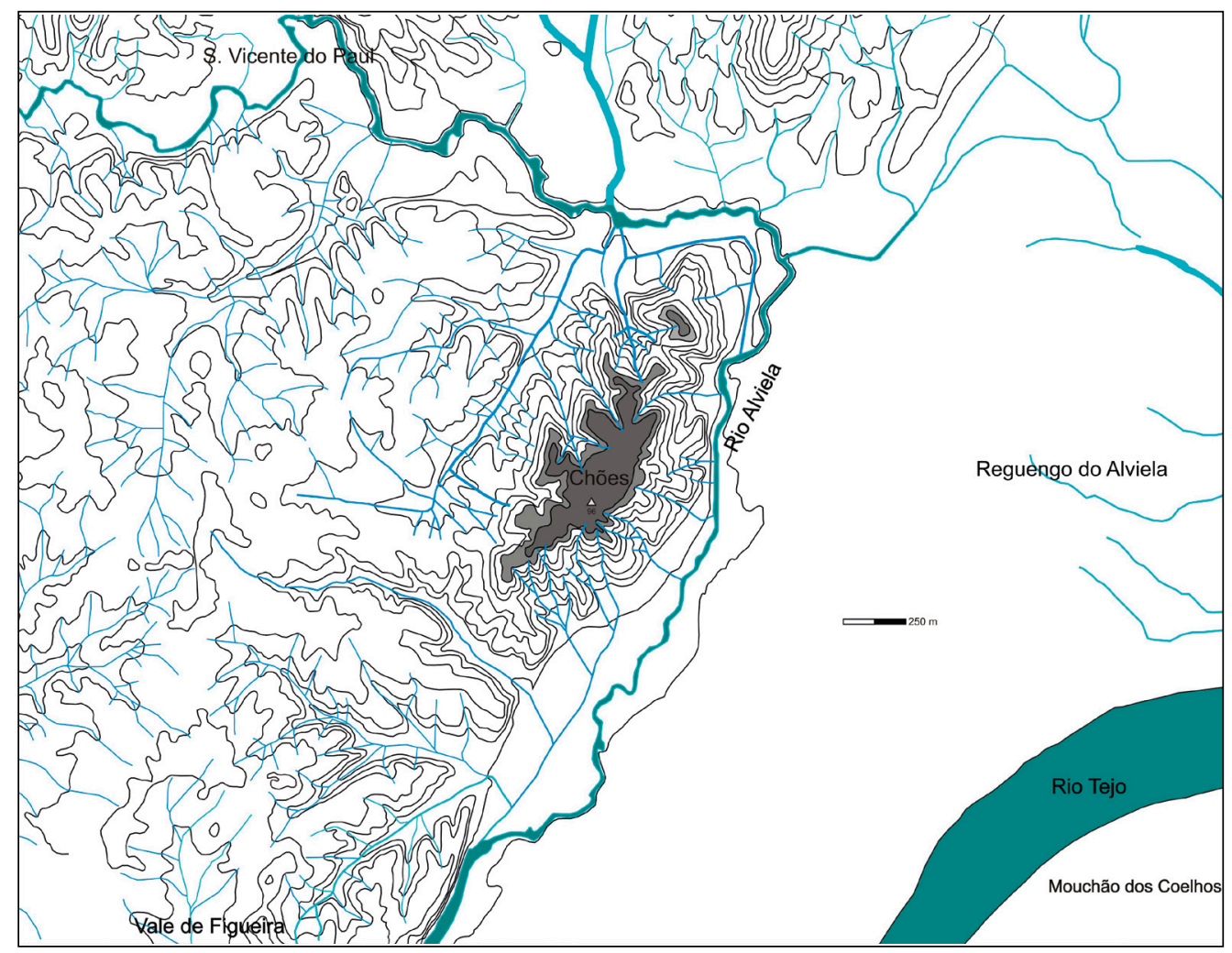

Figura 2. Planta da área de Chões de Alpompé, com as curvas de nível e localização das linhas de água produzida a partir da carta militar 1:25.000, folha $n .^{\circ} 341$ de 1969. Área de dispersão de materiais assinalada a cinzento

Figure 2. Map of Chões de Alpompé area, with contour lines and watercourses produced from the Portuguese Military Map 1:25.000, no. 341 from 1969. Dispersion area of materials marked in gray

prata e ouro, atestando assim uma ampla cadeia de transformação que releva o papel da dinâmica artesanal dos Chões (Fabião, Pereira e Pimenta, 2015). Uma das mais interessantes e enigmáticas peças do conjunto é um possível lingote, que apresenta uma marca representando um tríscele, representado em ambas faces (figura 3). O motivo do tríscele é omnipresente na «arte castreja» do noroeste peninsular, quer na ourivesaria (González-Ruibal, 2006-o7; Silva, 2007), quer na escultura (Calo Lourido, I994; González-Ruibal, 2004, 2006-07; Silva, 2007), sendo um motivo iconográfico totalmente ausente em regiões meridionais. Assim, afigura-se aceitável atribuir uma proveniência setentrional a este possível lingote, marcado com um símbolo frequentemente assumido como atributo de poder. Desta forma, é sugestiva a correlação desta peça com a expedição de Bruto, cognominado o Calaico, ao Noroeste peninsular onde este motivo decorativo é predominante (Fabião, Pereira e Pimenta, 2015).

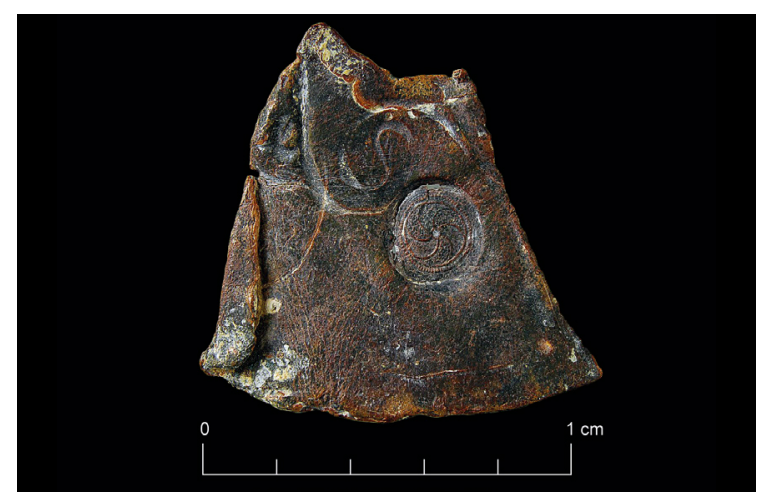

Figura 3. Possível lingote com tríscele gravado de Chões de Alpompé

Figure 3. Possible ingot with engraved triskele from Chões de Alpompé

A favor de uma instalação militar no local a partir do terceiro quartel do século in a. C. falam ainda outros artefactos metálicos, concretamente os que entram na categoria de militaria, como é o caso das glandes de chumbo, muito abundantes no sítio (II2 exemplares, figura 4), sendo de sublinhar 


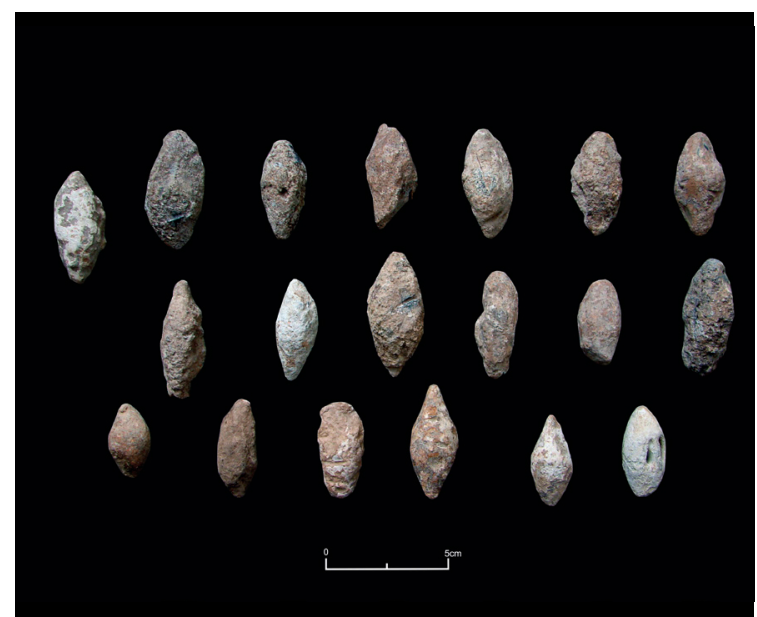

Figura 4. Conjunto de glandes de chumbo provenientes de recolhas no planalto dos Chões

Figure 4. Set of lead sling bullets from Chões de Alpompé

a demonstrada existência de uma oficina de fabrico de glandes plumbeae no local (Fabião, Pereira e Pimenta, 2015: II4-I29).

Apesar do precoce reconhecimento da importância dos Chões de Alpompé para o estudo do processo de conquista romana do território português, apenas em 2015 e 2016 foi possível realizar trabalhos arqueológicos devidamente enquadrados em um projeto de investigação, embora o contexto deste último estivesse relacionado com outras problemáticas, relacionadas com a ocupação da Idade do Ferro do estuário do Tejo. Dois dos cortes estratigráficos então realizados e as respectivas leituras estratigráficas permitiram demonstrar as hipóteses que tinham vindo a ser construídas com base nos materiais de superfície, concretamente:

I. O sítio teve uma relevante ocupação da Idade do Ferro de forte matriz orientalizante, que atravessou todo o primeiro milénio antes da nossa Era;

2. O planalto foi ocupado de forma intensa na segunda metade do século II a. C., notando-se uma forte componente itálica (Arruda et alii, 2018).

As questões que se prendem com o seu sistema defensivo, com taludes que correspondem a muralhas de terra, permanecem ainda em discussão. Apesar da sua existência ter sido constatada desde cedo, a dimensão, a planta e a(s) cronologia(s) de construção são ainda pouco claras. No decorrer dos levantamentos dos Serviços Geológicos de Portugal, efetuou-se, em i967, um reconhecimento no terraço fluvial dos Chões. Na sequência deste reconhecimento, foi publicado um trabalho ainda hoje incontornável para a compreensão deste singular sítio arqueológico e do seu sistema defensivo (Zbyszweski, Ferreira e Santos, 1968). As observações no terreno permitiram que os autores localizassem, na carta militar I:25.000, as áreas de dispersão de materiais então visíveis à superfície, assim como os restos dos taludes do sistema defensivo e das eventuais zonas de acesso (ver figura 2). Aduzindo ainda novos dados à problemática, «Em “Chões” ainda se podem observar, também, fora do campo principal, duas atalaias que aproveitariam também um terraço sobranceiro ao acampamento principal, do lado menos defensável.» (Zbyszweski, Ferreira e Santos, I968: 56). Tendo em consideração os dados cartográficos apresentados, estas duas atalaias localizar-se-iam no extremo Norte do planalto, no denominado Alto da Águia ou da Água.

$\mathrm{Na}$ escavação de 2015 , foi possível efetuar uma sondagem implantada na área exterior de um dos troços do talude que se encontra bem preservado, tendo sido possível identificar uma estrutura negativa a ele adossada, que foi interpretada como fosso e que se encontrava preenchida com materiais do período Romano-Republicano (Arruda et alii, 20I8: 2II) (figura 5).

Ficou assim comprovado que, durante o período Romano-Republicano, o sítio estava fortificado com uma muralha de talude e fosso. Contudo, a dimensão, a invisibilidade arqueológica que a densa vegetação impõe e as recentes explorações de saibro dificultam a compreensão da(s) planta(s) da fortificação.

Recentemente, no âmbito da realização da Carta Arqueológica de Santarém, o planalto dos Chões foi alvo de trabalhos de prospecção que conduziram à recolha de um vasto espólio arqueológico e a uma tentativa de levantamento e interpretação das evidências do seu sistema defensivo, que reproduzimos na figura 6 (Matias, 2018, Cd de anexo, Ficha relativa aos Chões). Neste levantamento, tal como, aliás, no anteriormente realizado por Zbyszweski e colaboradores (1968) (figura 7), é clara a existência, sensivelmente a meio do planalto, de um talude. Esta 


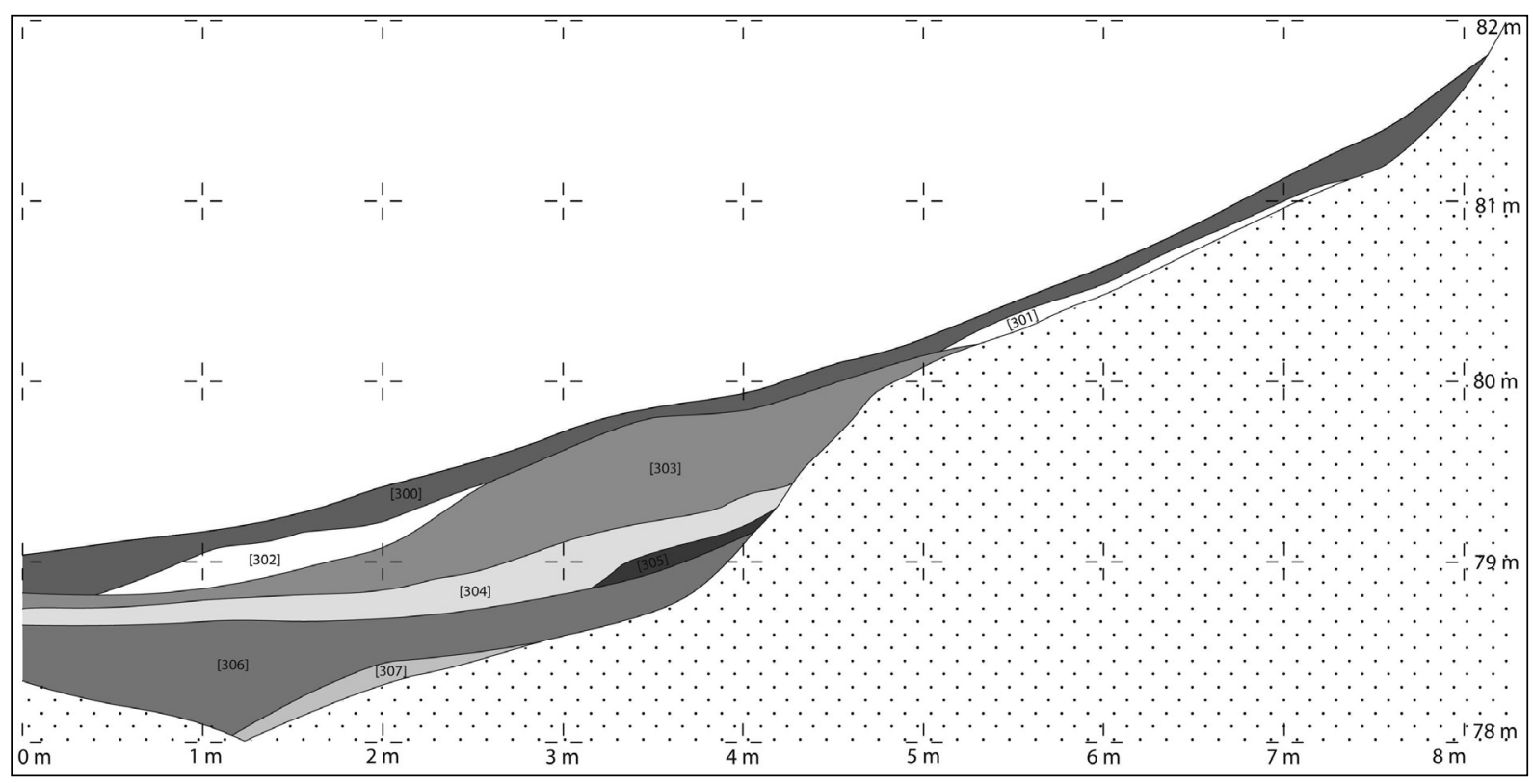

Figura 5. Perfil da estrutura negativa, junto à muralha Sudoeste, identificada na sondagem 4 (adaptado de Arruda et alii, 2018: fig. 11)

Figure 5. Profile of the negative structure, close to the Southwest rampart, identified in trench 4 (adapted from Arruda et al., 2018: fig. 11)

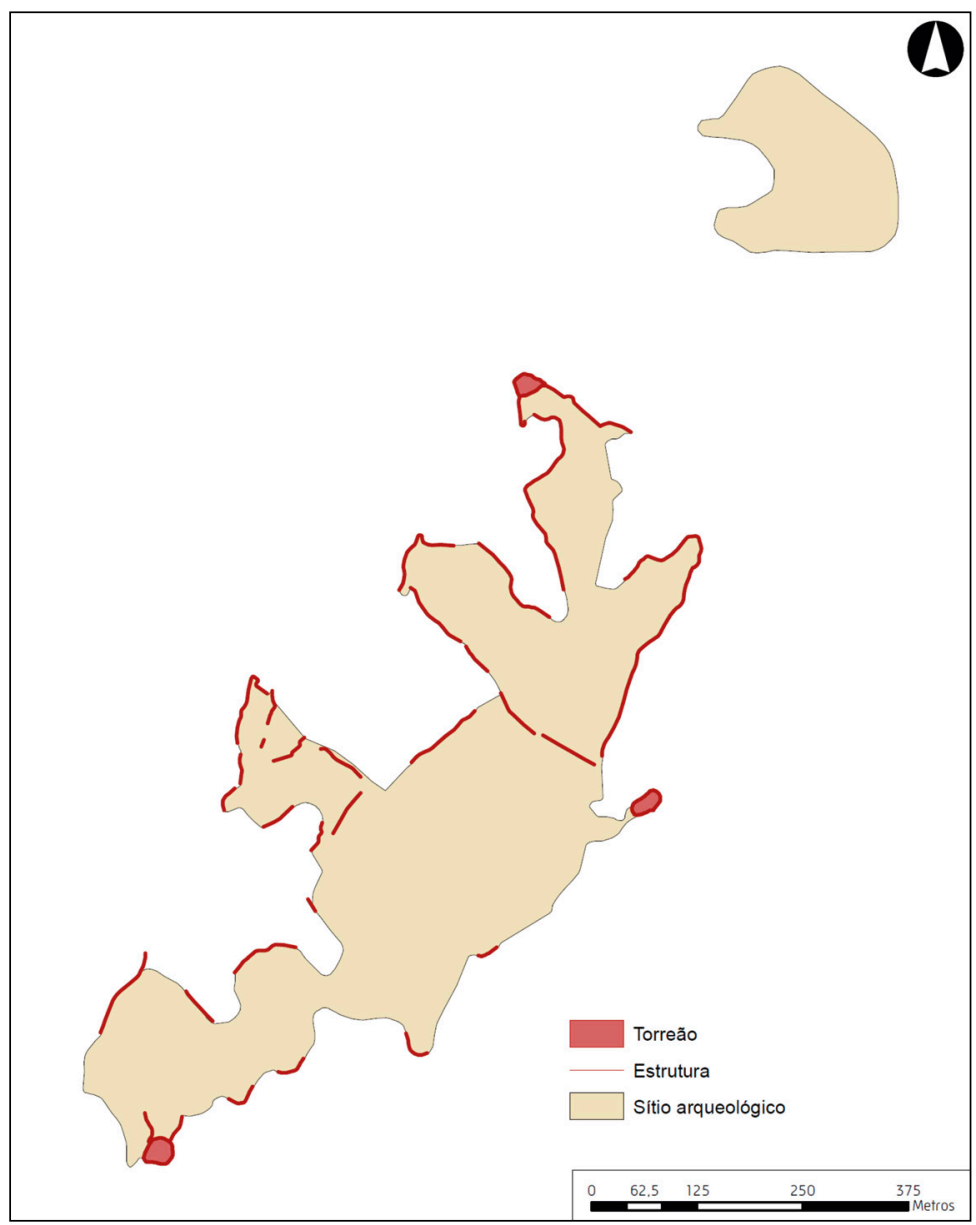

Figura 6. Planta de localização das estruturas defensivas identificadas no planalto dos Chões segundo Matias, 2018

Figure 6. Location plan of the defensive structures identified in Chões de Alpompé according to Matias, 2018 


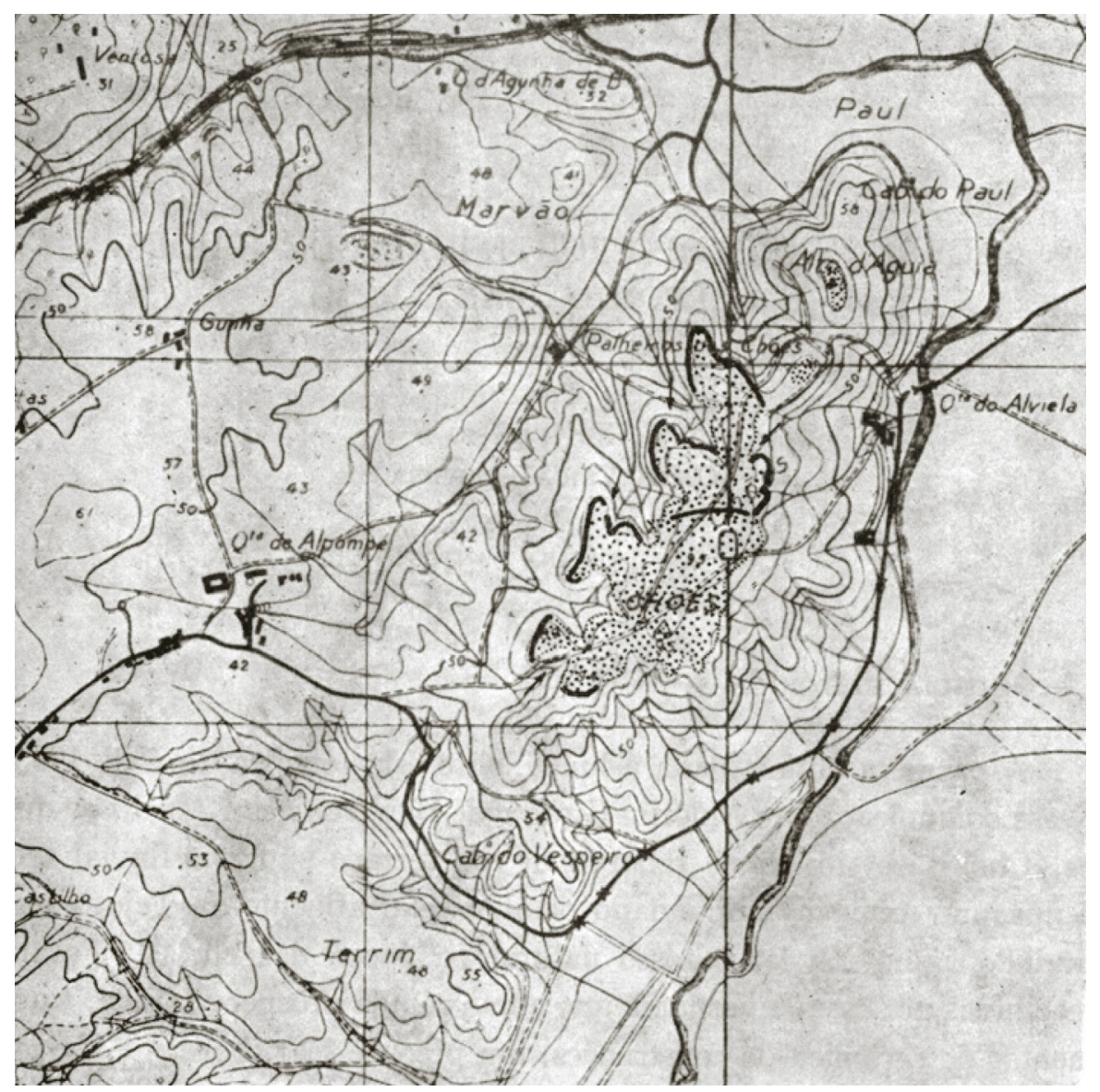

Figura 7. Planta de Chões de Alpompé, com a localização da área estimada do sítio, a ponteado, e dos taludes, a traço cheio, segundo Zbyszweski et alii, 1968, fig. 1

Figure 7. Chões de Alpompé plan, with the location of the estimated area of the site at dotted line, and the ramparts at full trace, according to Zbyszweski et al., 1968, fig. 1

estrutura foi já devidamente valorizada por Jorge de Alarcão, que levantou a hipótese de esta muralha poder corresponder a uma reutilização do recinto dos Chões (Alarcão, 2002: 39), o que provaria que o recinto militar poderia ter sido alvo de distintas utilizações.

Também os trabalhos de acompanhamento arqueológico da desmatação das vertentes, realizados em 2017 na área de proteção do sítio, permitiram acrescentar dados novos à questão do sistema defensivo de Chões de Alpompé (Pereira e Silva, 2020). Nesses trabalhos ficou claro o excelente estado de conservação do talude em grande parte da vertente Noroeste e Sudoeste. A destruição dos troços em falta pode explicar-se pela construção, em meados do século xix, da linha do Norte, que lhe passa próximo a Norte e Oeste, uma vez que nela se terão utilizado materiais (terra e pedra) daqui provenientes (Pereira e Silva, 2020: I7-I8, fig. 05).

\section{Metodologia}

\subsection{Detecção remota aérea e espacial}

O uso de detecção remota, uma ferramenta não invasiva, é cada vez mais frequente na investigação arqueológica e na gestão do património cultural, pois permite o mapeamento de sítios arqueológicos de forma multiescala e multitemporal, a rápida análise de vastos conjuntos de dados provenientes de múltiplas fontes e a monitorização dinâmica de paisagens arqueológicas (Luo et alii, 2019). Ainda que a deteç̧ão remota aérea e espacial, abrangendo os sensores passivos (medem a energia refletida pelo sol) e ativos (têm fonte de energia própria, e.g. feixe laser), não tenha sido especificamente desenvolvida para efeitos arqueológicos, a sua aplicação em arqueologia e no património cultural em geral tem já alguma tradição, sendo genericamente reconhecido o seu 
grande potencial na análise da dimensão «espacial» (Luo et alii, 2019). No entanto, são claras as suas limitações no âmbito da dimensão «temporal» (Luo et alii, 2019), não podendo, por isso mesmo, perder-se de vista a necessidade do uso de outras abordagens estritamente arqueológicas, que a complementem.

$\mathrm{O}$ varrimento laser aéreo ou LiDAR aéreo pode considerar-se uma das principais revoluções dos últimos anos no âmbito da detecção remota em arqueologia, tendo como principal vantagem a sua capacidade de penetrar através da vegetação e obter dados sobre as microtopografias ocultas (Opitz e Cowley, 2013). O mapeamento arqueológico a partir de imagens derivadas de laser aéreo tem por base fundamentalmente a aplicação de múltiplas técnicas de visualização aos modelos digitais de terreno (MDT) derivados a partir dos dados LiDAR para salientar as microtopografias e auxiliar, assim, a interpretação das formas arqueológicas. Estas técnicas de visualização variam entre simples sombreamentos (billshade) ou declives (slope), e técnicas mais complexas, como o local relief model, multi-scale relief model, openness ou sky-view factor (e.g. Devereux et alii, 2008; Doneus, 2013; Guyot et alii, 2018; Hesse, 20Iо; Orengo e Petrie, 20I8; Zakšek, et alii, 20II). Todavia, a grande diversidade de formas arqueológicas e os diferentes tipos de paisagens e de terrenos implicam que, para a obtenção de melhores resultados no mapeamento e na interpretação, as distintas técnicas sejam utilizadas em conjunto e de forma combinada (e.g. Bennett et alii, 2012; Challis et alii, 2oIr; Kokalj e Somrak, 20I9; Stular et alii, 20I2).

A combinação de dados de laser aéreo com imagens aéreas e de satélite aumenta exponencialmente a probabilidade de identificação de sítios arqueológicos, uma vez que a informação sobre a (micro-)topografia do terreno que o LiDAR aéreo fornece pode ser complementada pela espectral, facultada pela imagem. Assim, além da identificação de potenciais sítios arqueológicos que tenham uma expressão topográfica no terreno, é também possível identificar outros que, não tendo essa expressão (e.g. devido a erosão provocada por causas naturais ou antrópicas), podem, no entanto, ser percetíveis em imagens aéreas ou satelitais através de marcas provocadas nas culturas agrícolas (cropmarks) ou nos próprios solos (soilmarks).
A integração de fotografias aéreas históricas acrescenta dados fundamentais, no que à arqueologia diz respeito, concretamente no domínio diacrónico. Estas imagens aéreas poderão ser ortorectificadas através de técnicas de fotogrametria digital e visão computacional, desde que exista uma cobertura regular e sobreposição parcial entre as mesmas, permitindo, por um lado, análises multitemporais, e, por outro, documentar e analisar paisagens que foram fortemente modificadas em épocas recentes (Sevara et alii, 20I8). No caso de Portugal, temos disponíveis as que remontam à década de 40 e 50 do século xx (Redweik et alii, 20IO).

\subsection{O planalto dos Chões de Alpompé: os dados do LiDAR e da fotografia aérea histórica}

Os dados LiDAR de que dispomos para a zona do Baixo Tejo, inicialmente adquiridos para fins de investigação em sismologia e tectónica activa (Canora et alii, 20I5; Foroutan et alii, 20I6), têm uma densidade de aproximadamente 20 pontos por metro quadrado tendo em conta todos os retornos. As nuvens de pontos já se encontravam classificadas, pelo que os pontos do terreno estavam já identificados. Assim, foi possível extrair um modelo digital do terreno (MDT) com o,5 m de resolução espacial. Para tal, utilizamos o software @planlauf/TERRAIN ${ }^{1}$, que além de nos ter permitido interpolar o MDT directamente a partir das nuvens de pontos classificadas, permitiu-nos também gerar a partir do MDT um local relief model (Hesse, 20Io) para contrastar e ressaltar as microtopografias e facilitar o mapeamento e interpretação das estruturas arqueológicas. Este local relief resulta da diferença entre o referido MDT e o mesmo MDT com um filtro gaussiano aplicado.

Para a fotointerpretação do planalto dos Chões de Alpompé, optou-se pelas fotografias aéreas do voo SPLAL (Sociedade Portuguesa de Levantamentos Aéreos, Lda.), datadas de 1947, anteriores, portanto, à plantação do eucaliptal. Foram utilizadas para a produção da primeira série da cartografia militar nacional, tendo, para além do seu valor histórico,

1 planlauf/TERRAIN: https://planlaufterrain.com/ 

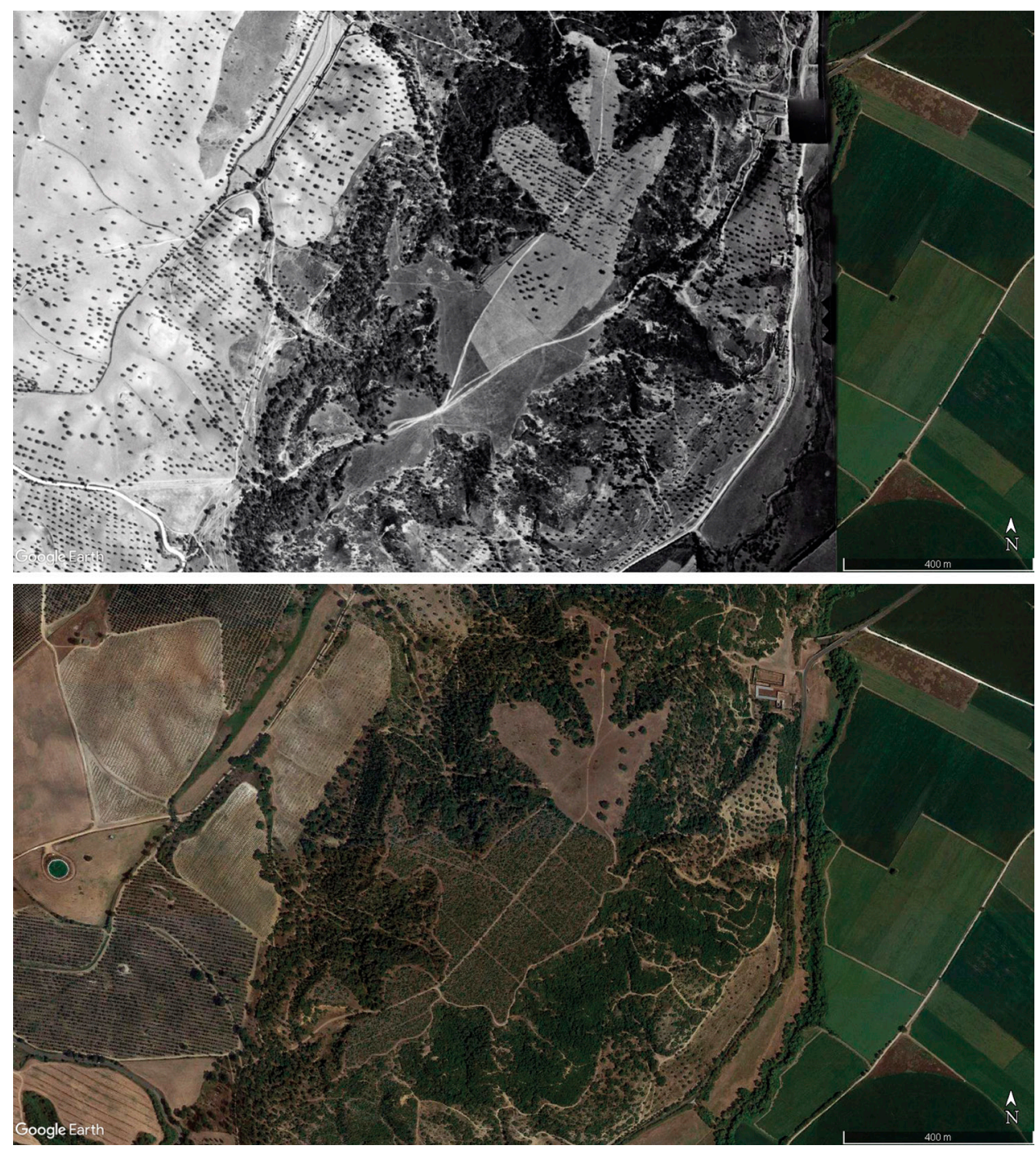

Figura 8. Em cima: ortofotografia do voo SPLAL de 1947 (CIGeoE); em baixo: ortoimagem de satélite de 2018 (๑Google Earth) do planalto dos Chões de Alpompé

Figure 8. Top: orthophotography of the 1947 SPLAL flight (CIGeoE); bottom: satellite orthoimage of 2018 (๑Google Earth) from Chões de Alpompé

também qualidade fotogramétrica (Redweik et alii, 2010). Desta forma, procedemos à restituição fotogramétrica das referidas fotos para uma melhor leitura e correlação entre estas e a restante informação geográfica disponível. Estas foram adquiridas em formato digital ao Centro de Informação Geoespacial do Exército (CIGeoE), tendo sido digitalizadas num scanner fotogramétrico de alta resolução (I20o dpi). Utilizámos o software (A)Agisoft Metashape para o processamento fotogramétrico das fotos aéreas, de forma a podermos extrair um modelo digital de superfície (MDS) e uma ortofoto (Gonçalves, 20I6). Uma vez que este software se destina a processar fotos obtidas por câmaras digitais, foi necessário realizar um pré-processamento das imagens, de forma a que todas tivessem a mesma dimensão em número de pixéis e o mesmo alinhamento em relação ao sistema óptico da câmara, usando as marcas fiduciais como referência (Blanco-Rotea et alii, 2016; Fonte e Costa-García, 2016; Fonte et alii, 20I7; Sevara, 20I3; Sevara et alii, 2018). Através da utilização de pontos de controlo identificados diretamente no (C) Google Earth foi possível extrair um MDS com o,66 m e uma ortofoto com 0,33 m de resolução espacial, ambos devidamente georreferenciados (figura 8). Este mesmo processamento foi aplicado às fotos do voo SPLAL dos sítios de Antanhol e do Alto do Castelo (figuras io e I4). 
Para efeitos comparativos, recorremos também ao uso das ortofotos digitais de Portugal disponibilizadas pela Direção-Geral do Território (DGT) através de Web Map Service (WMS) e às imagens de satélite disponíveis na plataforma (CGoogle Earth (figura 8).

A estes dados somámos os que resultaram de trabalhos de campo, de escavação e prospecção, nomeadamente os levantamentos efectuados pelas equipas dos serviços Geológicos de Portugal em meados do século passado (Zbyszweski et alii, i968) e da Câmara Municipal de Santarém, mais recentemente (Matias, 2018). Na proposta de interpretação que apresentamos para o planalto dos Chões de Alpompé, tivemos igualmente em consideração os resultados das escavações que se desenvolveram em 2015 (Arruda et alii, 2018) e do acompanhamento da desmatação das vertentes, efectuado em 2017 (Pereira e Silva, 2020).

\section{Deteção remota em Chões de Alpompé: a Arqueologia em debate}

\subsection{A ocupação humana dos Chões de Alpompé, modelos digitais e estrutura defensiva}

As novas imagens digitais do planalto dos Chões de Alpompé, permitindo confirmar a existência de muitas das estruturas já conhecidas, colocam em evidência outras que, até agora, não estavam identificadas ou não se valorizavam como vestígios das ocupações antigas do sítio. Porém, como foi anteriormente referido, estes dados geoespaciais expõem um mosaico global de vestígios, sem qualquer precisão cronológica, que só é possível averiguar através de metodologias estritamente arqueológicas.

Chões de Alpompé não oferece apenas uma única ocupação antiga. As recolhas de superfície indicavam que o planalto tinha sido ocupado durante o Paleolítico, o Calcolítico e a Idade do Bronze (Zbyszewski et alii, I968; Pimenta e Arruda, 20I4). Os trabalhos de escavação realizados em 2015 foram esclarecedores no que se refere à Idade do Ferro e à época Romana-Republicana (Arruda et alii, 2018: 222-223). A densa ocupação atestada durante o primeiro milénio a.n.e, sobretudo na segunda metade, deixou clara a forte probabilidade de que Móron possa, de facto, ter correspondido a este local, hipótese que era defendida por vários investigadores (Oleiro, 1953: 73-80; Zbyszewski et alii, 1968; Fabião, 2007: II7-II8), sendo agora, à luz dos dados obtidos nos recentes trabalhos de campo, mais provável que aí se tenha instalado, de facto, o acampamento de Décimo Júnio Bruto.

Os materiais que conhecemos até ao momento apontam também nesse sentido. As ânforas remetem para uma ocupação do planalto em meados do terceiro quartel do século II a. C. (Diogo, I982; Fabião, 2002; Ferreira et alii, 1993; Diogo e Trindade, 1993-94), cronologia compatível com a da cerâmica de verniz negro itálico (Zbyszewski et alii, 1968: 55; Garcia, 1977: 70-71; Arruda et alii, 2018: 216).

Todavia, o vasto conjunto de materiais que conhecemos do sítio contrasta fortemente com o atual $\mathrm{co}^{-}$ nhecimento da arquitectura e das construções. Desde há longa data que sabemos da existência de taludes de terra nos limites do planalto (Oleiro, 1953: 73-80; Saa, I956: 209; Zbyszewski et alii, I968), associados a plataformas exteriores de onde foi extraída a terra para construção daquelas estruturas e onde se pôde documentar a presença de negativos paralelos à muralha (Arruda et alii, 2018: 224). Estas construções defensivas são particularmente visíveis a Noroeste do planalto. Nas imagens que agora se apresentam, podemos ver claramente a combinação de um talude de terra e de um terraço que lhe é paralelo (figura 9), atingindo em algumas zonas 8 metros de altura conservada (Arruda et alii, 20r8: fig. 22; Pereira e Silva, 2020: fig. II). Não é improvável que esta estrutura recorresse a materiais perecíveis para manter a sua integridade ou, inclusive, para formar uma paliçada, conformando-se, assim, o sistema agger. Trata-se, portanto, de um sistema defensivo típico de época Romana-Republicana, documentado em recintos militares datados da segunda centúria a.n.e, como é o caso dos de La Gran Atalaya de Renieblas (Blázquez Martínez, I999: 98; Morillo Cerdán, 2003: 54-57) ou da circunvalação de Numancia (Morillo Cerdán, 2003: 50-54; Morillo Cerdán e Morales Hernández, 20I6: 280-28I), embora 


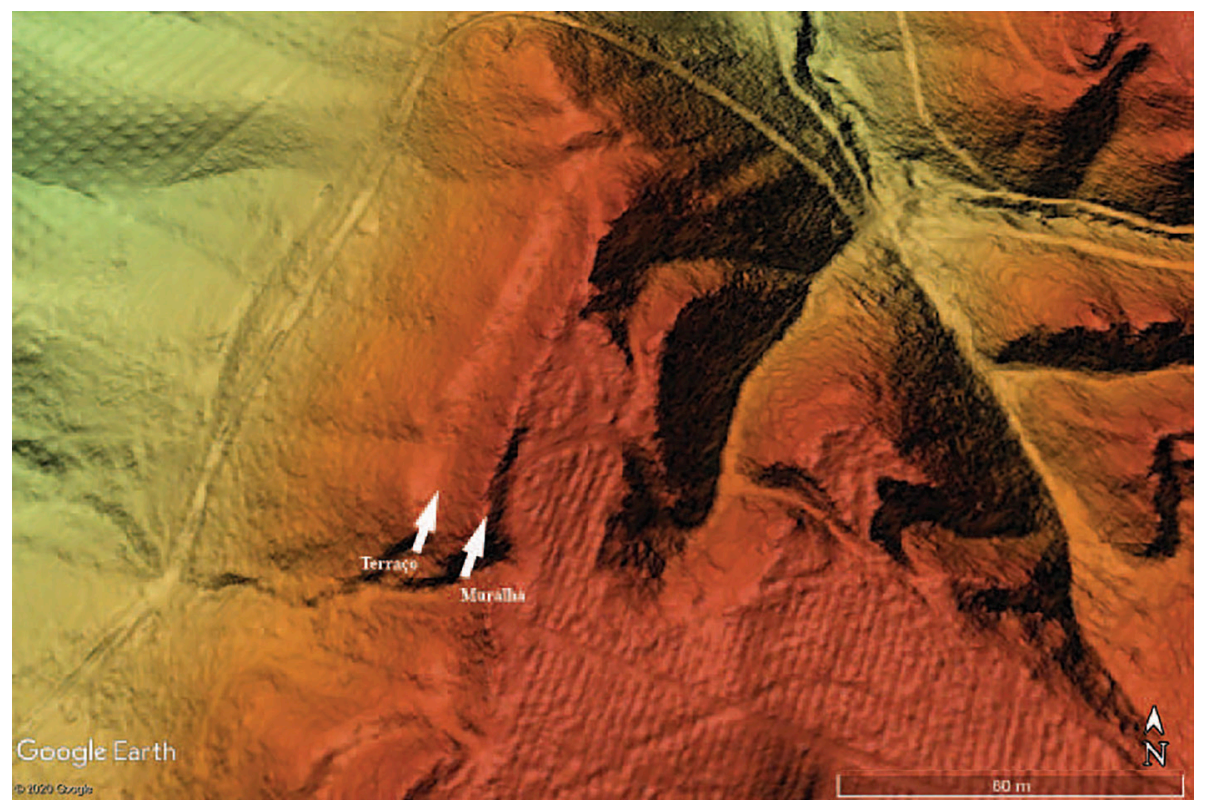

Figura 9. Terraço e muralha de terra no limite Noroeste do planalto dos Chões

Figure 9. Terrace and earth rampart on the north-western edge of the Chões de Alpompé plateau

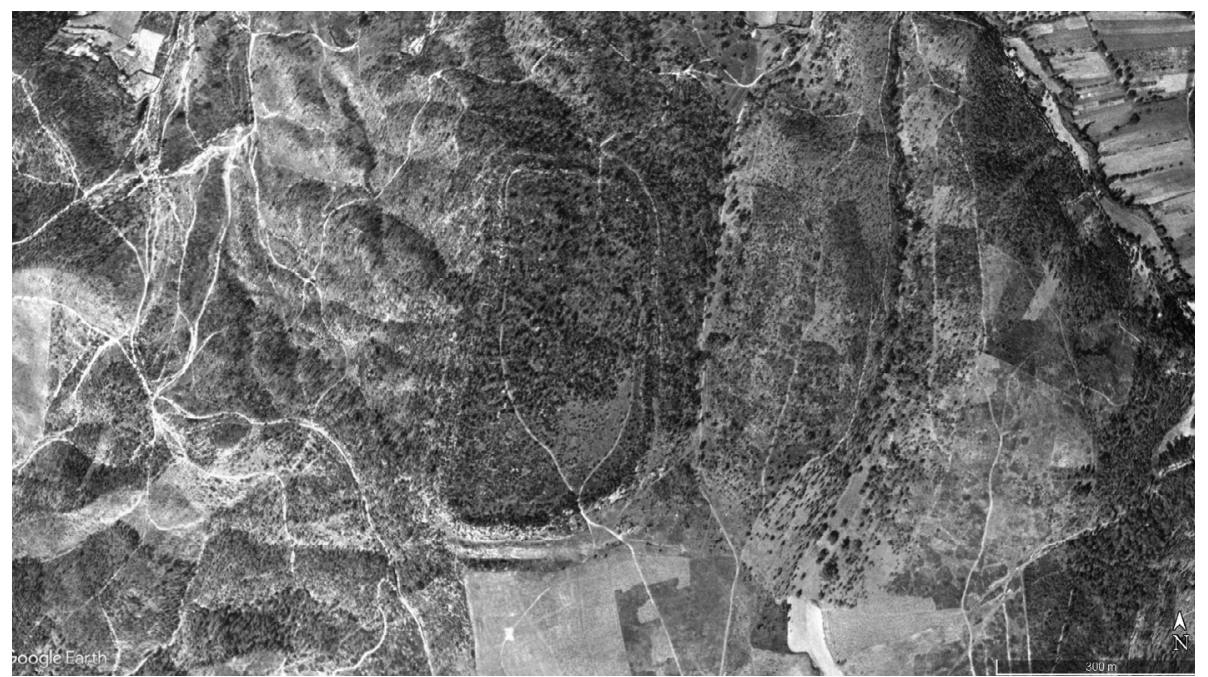

Figura 10. Ortofoto do voo SPLAL de 1947 (CIGeoE) do recinto de Antanhol

Figure 10. 1947 SPLAL flight orthophoto (ClGeoE) of the Antanhol enclosure

sejam mais raros os recintos delimitados por muralha de terra, como seria o caso do acampamento de Antanhol, no vale do Mondego (Fabião, 2007: I15-ır6; Leitão, 2014: 79) (figura Io).

A utilização de terra para a construção de acampamentos militares não é exclusiva destes sítios portugueses, nem utilizada unicamente durante o século ir a. C. Nas imediações de Hermeskeil, em Trier-Saarburg, foi registado um recinto militar, de meados do século i a. C. relacionado com a conquista da Gália, que oferece as mesmas características, ainda que apresente distinta planimetria (Harnung, 2015: 2IO-2I2). Com efeito, ali o sistema defensivo foi elevado recorrendo à terra proveniente das imediações e da escavação do fosso, negativo que assume dimensões idênticas às de Chões, ostentando, contudo, um perfil mais encaixado (Harnung, 2015: 213, abb. 5). O autor relaciona este tipo de construção com o tempo útil do recinto militar, uma vez que o sistema defensivo construído não seria plenamente eficaz em caso de permanência prolongada. Partindo deste pressuposto e assumindo que o sistema defensivo dos Chões de Alpompé corresponde 
à instalação de Décimo Júnio Bruto, também neste caso tratar-se-ia de uma construção temporária, embora o caso português evidencie condições de defensabilidade bem mais eficazes.

\subsection{As muralhas Noroeste e Sudeste e os torreões}

Apesar de a existência de uma muralha de terra ao longo do perímetro da elevação (figura II) ser evidente, a sua configuração exata não é fácil de determinar, uma vez que esta se encontra interrompida em vários tramos. Se bem que a situação pareça derivar da erosão contínua do planalto, não podemos deixar de colocar a hipótese de essas faltas resultarem da exploração dos recursos necessários para a construção da linha de caminho-de-ferro do Norte, inaugurada em I862 (Pereira e Silva, 2020: I6-I7), que passa a escassa distância, a Oeste e a Norte. Sabemos que para a referida construção se recorreu à importação de produtos industriais, mas a extração de balastro foi frequente a nível nacional (Pinheiro, I988: 753-754), o que permite admitir a sua exploração local, uma vez que, por um lado, é aí abundante e, por outro, a microtopografia das vertentes a Noroeste parece evidenciar tal exploração que, irremediavelmente, destruiu o sistema defensivo romano-republicano em algumas zonas.

Esta hipótese assenta também nos resultados obtidos no acompanhamento arqueológico realizado durante os trabalhos de desmatação das vertentes. Nestas áreas, registaram-se grandes concentrações de materiais (Pereira e Silva, 2020), sobretudo de época romana-republicana, como é o caso de um caccabus trípode e de um unguentário itálico fusiforme (figura I2), mas também da Idade do Ferro e, eventualmente, do Bronze Final. Estas concentrações resultam evidentemente de escorrências, situação que não foi verificada nas vertentes onde se conservam os panos de muralha, tendo apenas paralelo na área Sul, justamente no local onde a exploração de saibro terá destruído um dos acessos ao recinto (Zbyszewski et alii, I968: 58, fig. I).

Situação distinta, no que ao sistema defensivo diz respeito, seria a do limite Sudeste, área voltada para o rio Alviela e para a Lezíria. Aí, não se constata a presença de muralhas imponentes ou de terraços escavados para construir o talude de terra. $\mathrm{Na}$ verdade, as vertentes são consideravelmente mais íngremes, oferecendo evidentes condições

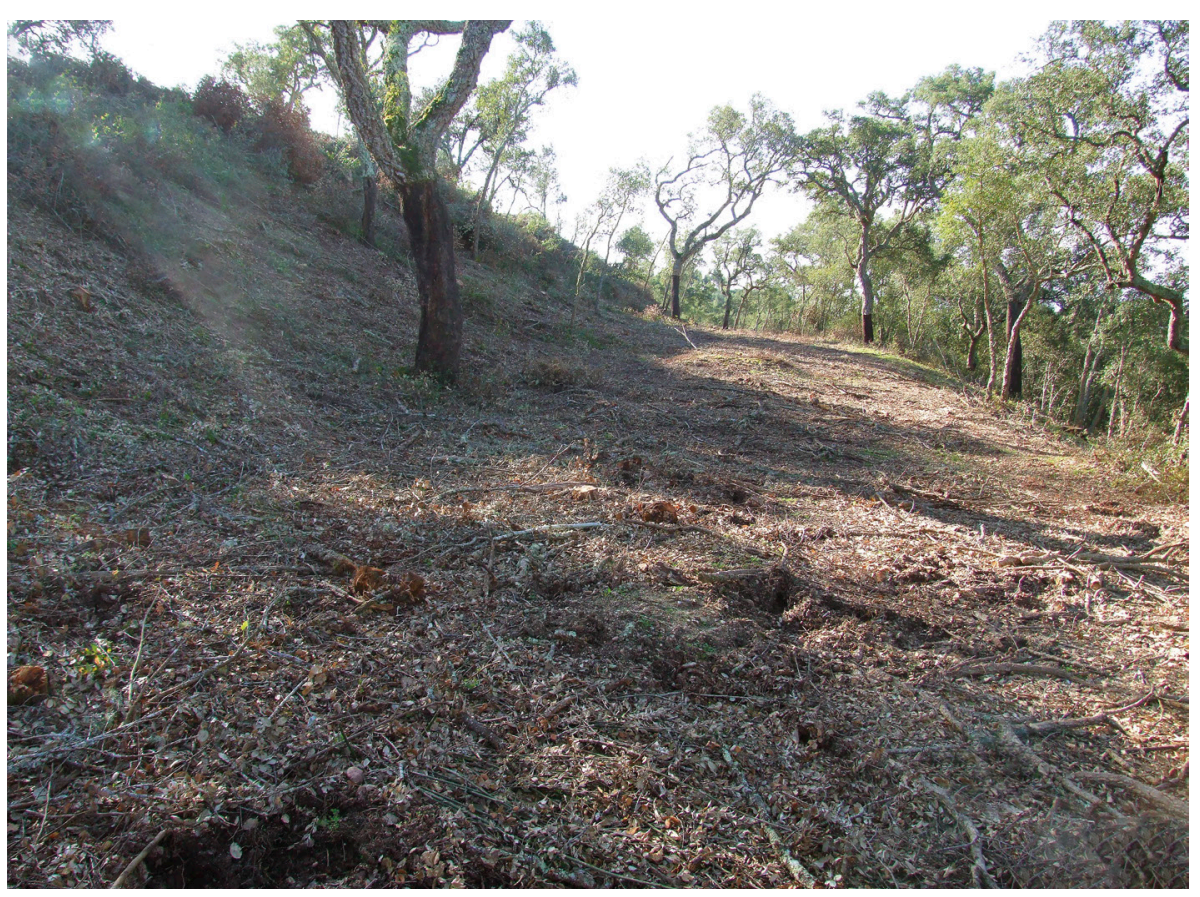

Figura 11. Terrapleno e paramento exterior da muralha Oeste, Oeste-Noroeste

Figure 11. Outer wall of West and West-Northwest rampart 


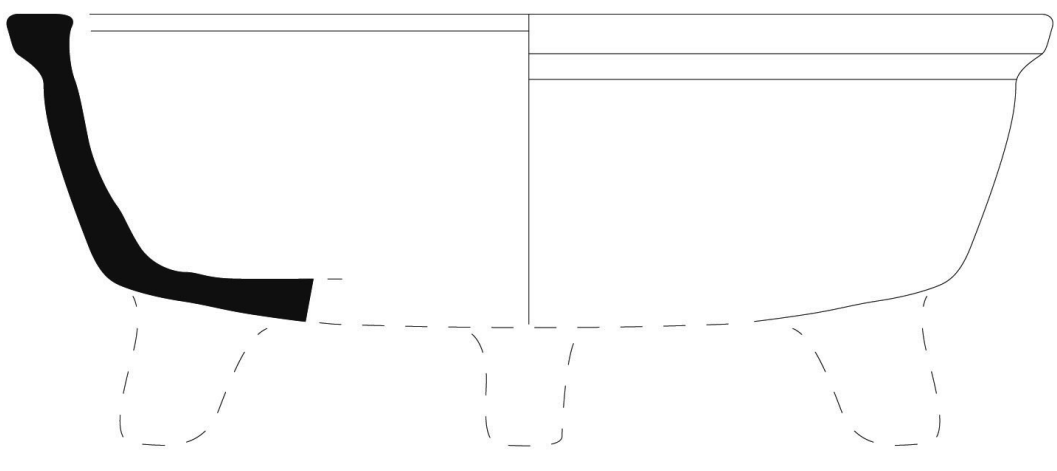

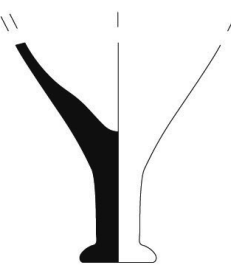

CALP 2015/16

009

CALP 2015/16

005

0

$10 \mathrm{~cm}$

Figura 12. Caccabus trípode e unguentário itálico recolhidos durante os trabalhos de acompanhamento da desmatação das vertentes do planalto (Pereira e Silva, 2020: 15, fig. 14)

Figure 12. Tripod caccabus and italic unguentarium collected during the deforestation monitoring work in the slopes of the plateau (Pereira e Silva, 2020: 15, fig. 14)

de defensabilidade natural, não exigindo, por isso mesmo, o mesmo empenho na construção do sistema defensivo.

A planta do recinto militar oferece um traçado irregular, situação que sugere que a sua implantação se adaptou à morfologia do planalto, mas há, apesar de tudo, uma certa linearidade. Por outro lado, e apesar das destruições resultantes das eventuais explorações de balastro, há dados que permitem admitir que o recinto militar ocuparia a totalidade do planalto (figura 13), aproximando-se, assim, dos 30 ha (Pereira e Silva, 2020: I8, fig. 05), área que se assemelha à dos acampamentos de Renieblas (acampamento III), de Almazán ou de Navalcaballo (Morillo Cerdán, 2003: 70).

O recinto estaria complementado por torreões (Zbyszewski et alii, 1968; Matias, 2018), que aproveitaram a topografia natural, correspondendo a esporões que sobressaem dos limites do planalto e que funcionavam, eventualmente, como atalaias. A mais recente proposta (Matias, 20I8: fig. 4) identifica três estruturas deste tipo. A sua localização permite admitir que estariam próximo das zonas de ingresso ao recinto militar. A utilização estratégica destas elevações também não é inédita em acampamentos militares romanos do século II a. C. (Morillo Cerdán e Morales Hernández, 20I6: 286-288).
As características deste recinto, das técnicas construtivas do sistema defensivo, da estratégia de implantação e das dimensões não parecem, de facto, inviabilizar a correlação deste local com aquele que terá sido utilizado pelo cônsul da Ulterior. Estes dados compaginam-se, por outro lado, com os espólios conhecidos, resultantes de prospecções, (Fabião, 1989; Fabião et alii, 2015; Pimenta e Arruda, 20I4), mas também de escavações recentes (Arruda et alii, 20I8), que têm abundantes paralelos datados da segunda metade do século ir a. C., bem como, aliás, a própria planimetria do recinto (apenas alguns exemplos: Sanchéz-Lafuente Pérez, 1979; Morales Hernández, 200o; Gómez Pantoja e Morales Hernández, 2002; Luik, 2007).

Não podemos, no entanto, deixar de chamar aqui a atenção para as semelhanças entre as técnicas de construção do sistema defensivo de Chões de Alpompé e as que foram reconhecidas no Alto do Castelo, em Alpiarça (figura I4). Com efeito, ambos sítios conservam muralhas elevadas com recurso a sedimentos locais, ainda que no último caso a planta tenha uma forma distinta e o recinto esteja envolvido por um duplo fosso (Kalb e Höck, 1982; 1983; 1986). Todavia, e como foi já referido, esta solução arquitectónica pode resultar, também, da própria (in)disponibilidade de recursos naturais (Fabião, 2007: II8), não sendo argumento suficientemente válido para assumir a contemporaneidade 


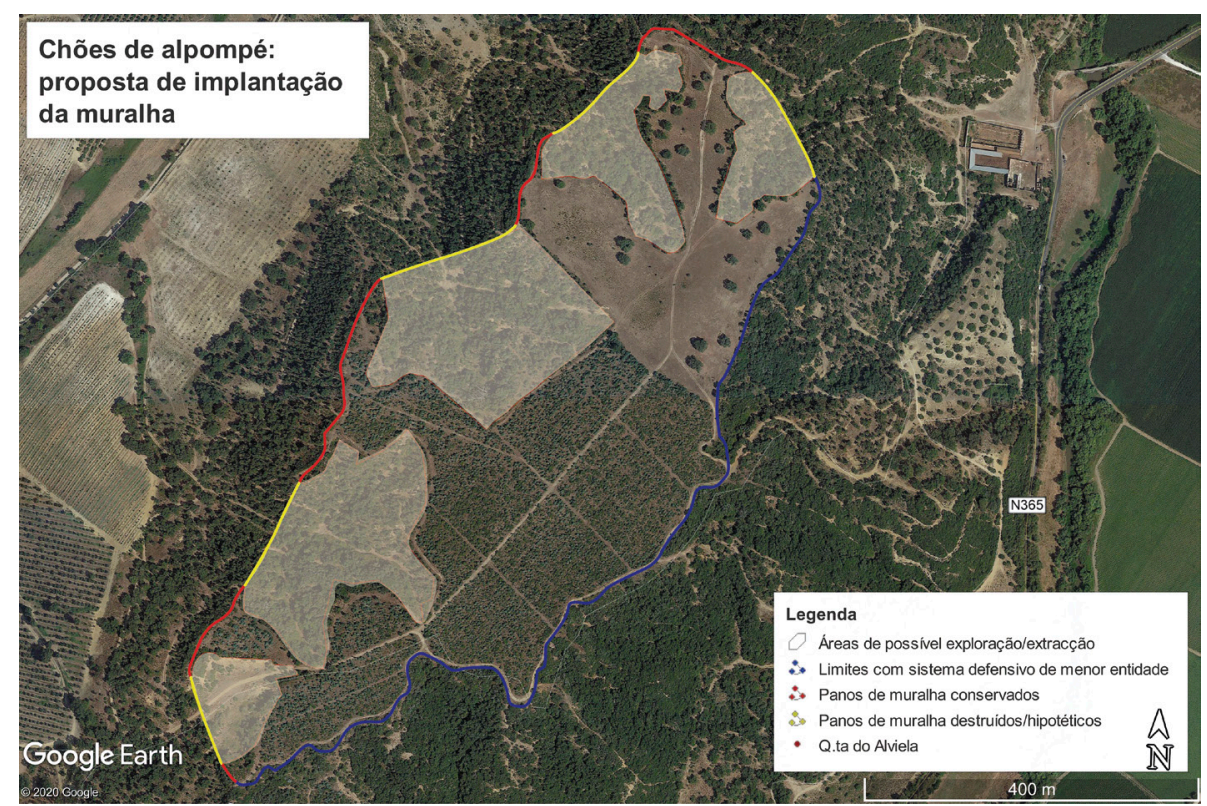

Figura 13. Proposta da extensão do recinto militar (a partir de Pereira e Silva, 2020)

Figure 13. Proposed extension of the military enclosure (from Pereira e Silva, 2020)

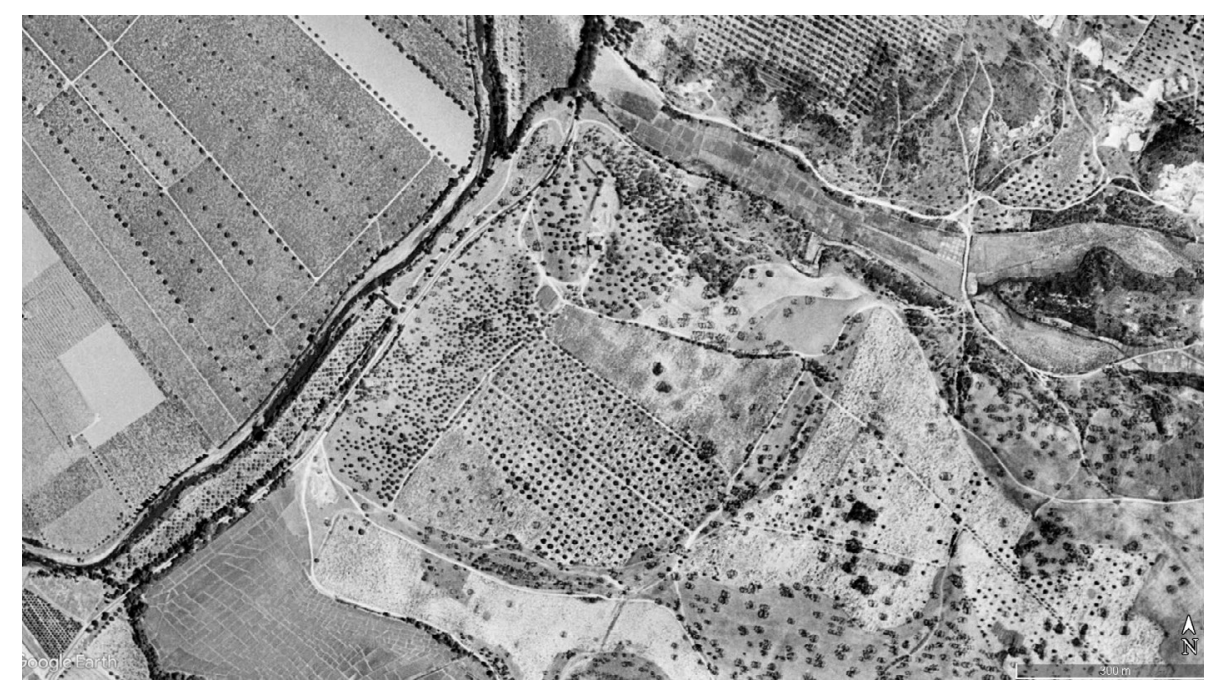

Figura 14. Ortofoto do voo USAF de 1958 (CIGeoE) do recinto do Alto do Castelo

Figure 14. USAF flight 1958 (CIGeoE) orthophoto of the Alto do Castelo enclosure

de ambos. Aliás, o mesmo sistema defensivo, ou seja, terrapleno associado a fosso ou duplo fosso, foi documentado nos acampamentos de Burgo de Osma (García Merino, 1996; 2007:324-325) e de Navalcaballo (Núñez Marcén, 1998; Morillo Cerdán, 2003), em Soria, ambos de cronologia consideravelmente mais recente.

\subsection{Discussão dos resultados}

O traçado das defesas perimetrais do recinto de Chões de Alpompé é de leitura relativamente consensual, vindo o levantamento LIDAR dar-lhe mais solidez, esclarecendo-o e clarificando-o. Já as estruturas no interior do recinto, aparentemente correspondendo também a construções defensivas, vêm aduzir complexidade ao sítio e às suas ocupações de índole castrense. Porém, algumas das anomalias observadas nas imagens podem ser resultado da actividade agrícola continuada no sítio, como parece ser o caso de alguns caminhos que atravessam o planalto, ainda visíveis na ortofotografia aérea do voo SPLAL ou conservados no terreno (figuras 8 e 15 ). 


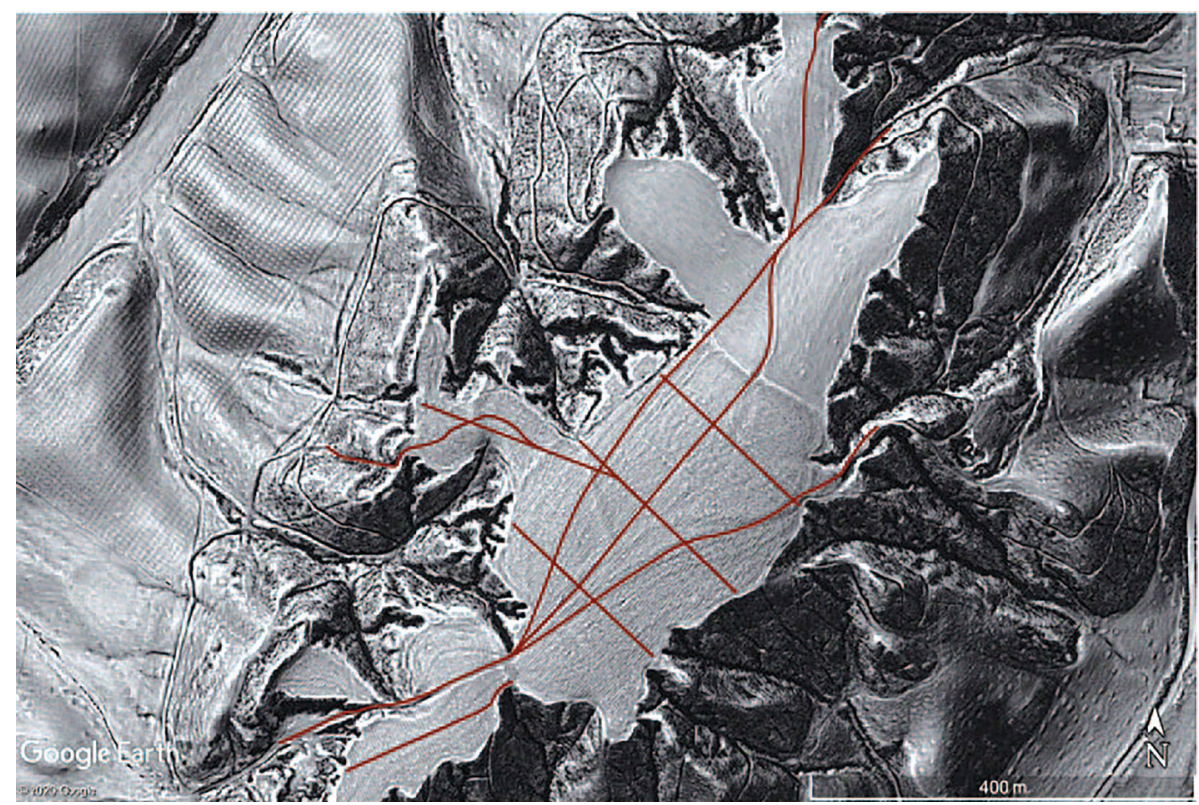

Figura 15. Anomalias identificadas coincidentes com caminhos antigos e recentes

Figure 15. Anomalies identified coinciding with old and recent paths

$\mathrm{Na}$ zona central do planalto, são visíveis taludes que parecem delimitar um espaço concreto, de planta grosseiramente retangular (figura I6), cuja interpretação é difícil sem os necessários trabalhos de escavação. Ainda assim, esta estrutura merece um comentário, até porque um desses taludes, cedo identificado (Alarcão, 2002: 39), mantém ainda alguma expressão no terreno. O levantamento LiDAR permitiu detectar a presença de outros, paralelos e perpendiculares ao primeiro, que estão invisíveis no campo. O talude situado mais a Sul descreve uma linha curva, bem marcada, que remete para o contorno dos recintos militares romano republicanos. Se considerarmos o talude central como limite deste recinto, pode considerar-se que esta estrutura corresponde a um recinto militar de menor entidade, com aproximadamente seis hectares, excluindo os possíveis reforços, podendo associar-se a uma utilização militar do sítio posterior à campanha de Bruto. Apesar disto, não podemos descartar a hipótese de o mesmo se prolongar mais para Norte.

Tal como referimos antes, o planalto dos Chões de Alpompé, devido à sua posição geoestratégica, pode ter tido distintas ocupações militares durante o período romano republicano. Neste debate, ganha particular interesse o conjunto numismático recolhido no sítio (Diogo e Faria, 1985; Ruivo, 1999), recentemente abordado e reinterpretado por Carlos Fabião (20I4: I3-I6). Recorde-se que este, juntamente com o material cerâmico (Fabião, I989; Pimenta e Arruda, 20I4; Arruda et alii, 2018), não deixa dúvidas sobre uma ocupação centrada em meados do terceiro quartel do século II a. C. (Fabião, 20I4: I2-I3). Todavia, o referido conjunto, engloba um considerável número de numismas mais tardios que permitiram sugerir que o local tenha sido abandonado «durante os primeiros anos do conflicto sertoriano (c. 80-78 a. C.)» (Ruivo, 1999: 106). O mesmo pode ser dito para o espólio cerâmico, uma vez que algumas ânforas cabem em tipos relativamente recentes, com cronologias já centradas no século i a. C., como são as Mañà $\mathrm{C}_{2} \mathrm{~b}$, as Dressel $\mathrm{IC}$ e as ovóides do vale do Guadalquivir (Pimenta e Arruda, 20I4).

Os materiais mais antigos (Pimenta e Arruda, 20I4: 387), contemporâneos da fase correspondente ao grande recinto militar de planta irregular, são relativamente fáceis de definir do ponto de vista cronológico, até porque nos podemos socorrer dos dados contextualizados do Castelo de São Jorge (Pimenta, 2005) ou dos níveis fundacionais de Valência (Ribera i Lacomba, I998; 2002). Para os mais recentes, eventualmente datados dos primeiros anos da primeira guerra civil, e na ausência de contextos seguros, a questão é mais complexa, apesar dos 

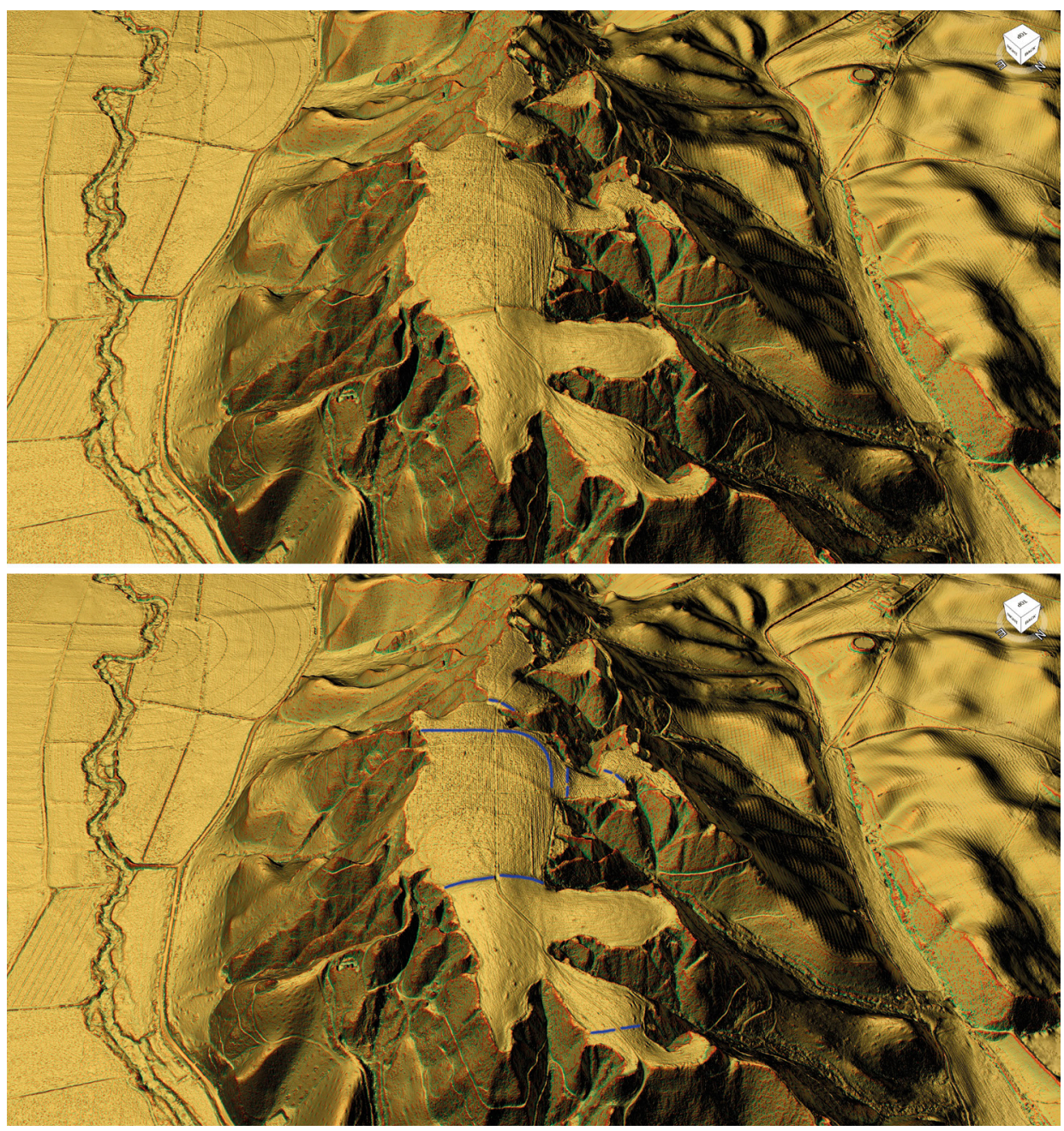

Figura 16. Foto-interpretação do recinto de planta rectangular de Chões de Alpompé

Figure 16. Photo-interpretation of the rectangular enclosure of Chões de Alpompé

paralelos que se podem obter em Cáceres el Viejo (Ulbert, I984) ou nos níveis de destruição de Valência (Alapont Martín et alii, 2oro). De facto, alguns dos contentores anfóricos, bem como, aliás, os artefactos metálicos, apenas fornecem cronologias seguras quando estão devidamente contextualizados, ou, em casos excepcionais, de ocupações curtas (Fabião et alii, 2015: 143). E assim torna-se difícil perceber se o local foi continuamente ocupado ou se, pelo contrário, terá existido um hiato entre as duas ocupações.

No entanto, e como claramente atestam as moedas, não existem quaisquer dúvidas sobre o facto de Chões de Alpompé ter tido uma ocupação durante o primeiro quartel do século i a. C., momento de grande instabilidade no Ocidente, que exigiu uma forte presença militar. A localização estratégica do sítio e a sua importância para os exércitos consulares foi já valorizada por José Ruivo (I999: I06), investigador que não esqueceu que a situação só se alterou quando Scallabis adquiriu estatuto colonial.

Apesar da destruição de parte de um dos taludes, não parece improvável que os que foram agora identificados pela detecção remota possam ter integrado um eventual recinto militar de planta ortogonal construído no momento mais tardio, hipótese que só escavações arqueológicas podem confirmar.

Deve ter-se igualmente em consideração que a maioria dos materiais parece evidenciar uma forte relação com a Ulterior, o que demonstra que o sítio pode ter estado em ambos momentos sob a égide de Roma: primeiro como ponto de apoio à campanha de Décimo Júnio Bruto, depois como eventual ponto de apoio durante os conflitos sertorianos e controlo do trânsito fluvial do Tejo. 


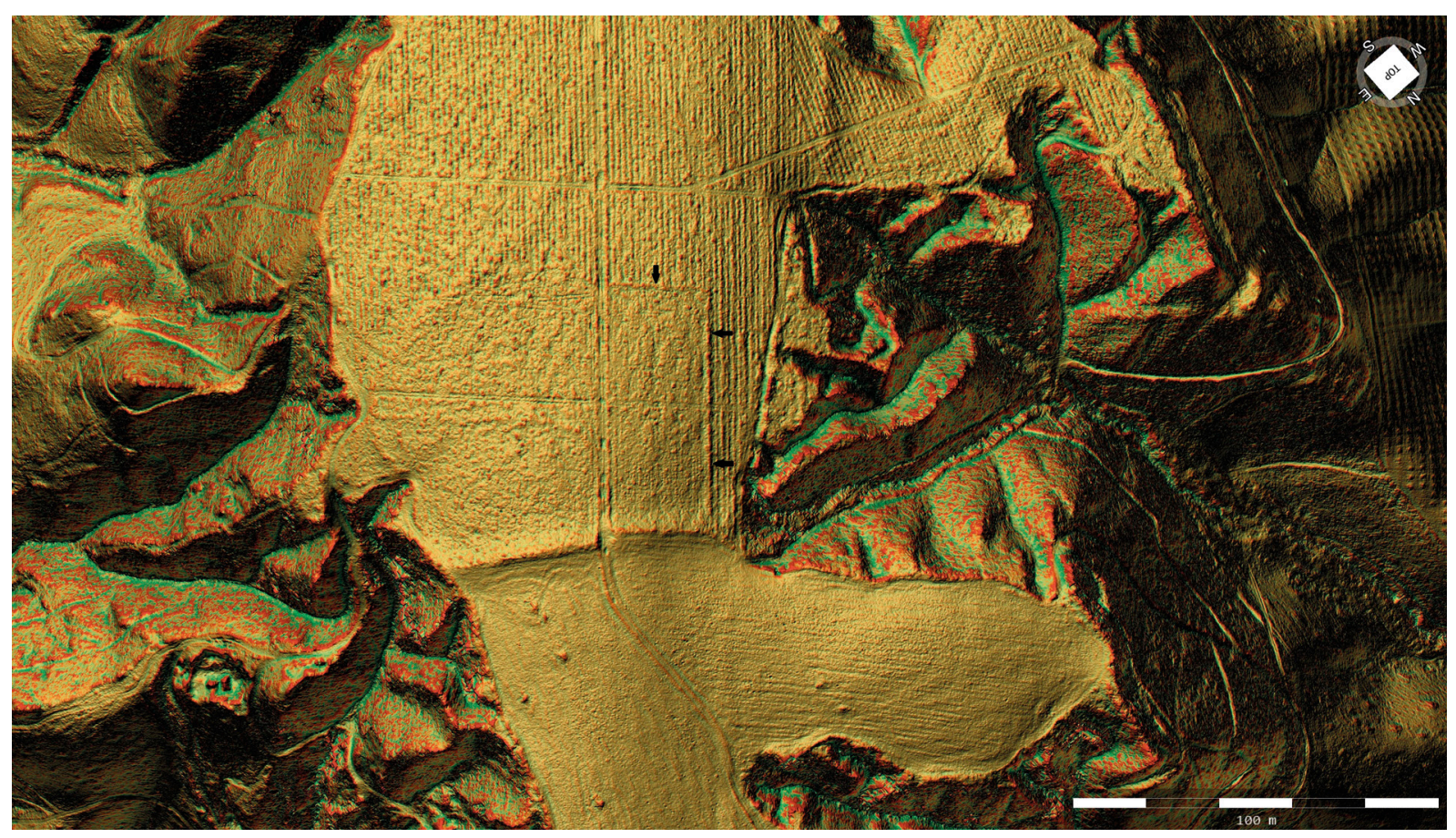

Figura 17. Estrutura na zona central do planalto, evidenciada com setas a preto

Figure 17. Structure in the central part of the plateau, highlighted with black arrows

Importa ainda ter presente a recente análise da documentação medieval, que permitiu identificar uma referência ao sítio no século XII (Pimenta, Henriques e Mendes, 20I2). Na crónica de Dom Afonso Henriques de Duarte Nunes de Leão, ao relatar-se a campanha militar desencadeada em Iı84 pelo Miramolim de Marrocos AbenIacob, mencionou-se:

E todos vierão per Alentejo. E passando o rio, dia de Sam Ioam Baptista daquelleanno de M.CLXXXIIII. Nesse mesmo dia forão sobre o castello de Torres Novas, e o destruirão. Aa segunda feira vierão poer ser arraial em hum monte, que chamão de Pompeio. (Leão, I975: 92).

Face à descrição geográfica, parece evidente que este monte que «chamão de Pompeio» corresponde a Alpompé, nome pelo qual o sítio é hoje conhecido. A referência expressa neste manuscrito a um Monte de Pompeio, leva-nos a retomar a questão da análise linguística na formação do topónimo Chões de Alpompé, aliás já levantada por Dias Diogo (Diogo, 1982: I49). Terá subsistido em $\mathrm{Al}$-pompéa referência a um eventual acampamento romano de Pompeu Magno?
A par das anomalias relacionadas com os sistemas defensivos, o levantamento LiDAR da plataforma dos Chões é bastante pobre no que se refere à sua organização interna, situação que poderá explicar-se pela contínua exploração agropecuária, por um lado, e pela própria geologia, por outro, esta última consubstanciada na escassez de elementos pétreos, que condicionou a forma de construir. Contudo, nas imagens LiDAR vislumbra-se a existência, em posição central e alinhada com um dos principais caminhos que atravessa o planalto, de um amplo recinto retangular, medindo uns expressivos $122 \mathrm{~m}$ de comprimento por $50 \mathrm{~m}$ (figura I7). Em concordância com esta leitura, constatou-se, no terreno, a presença de blocos de calcário branco, bem talhados. Sem a realização de trabalhos arqueológicos, não é possível verificar se esta evidência se reporta diretamente a edifícios da Antiguidade ou a alguma ocupação mais recente. Mas, tendo em consideração o conhecimento de que dispomos sobre a arquitetura militar do período Romano-Republicano, a existência deste recinto é sugestiva, bem como a sua planimetria e localização. Poderia tratar-se do Principia ou Praetorium do acampamento ou, pelo contrário, será antes uma estrutura mais recente relacionada com o uso agropecuário do planalto dos Chões? 


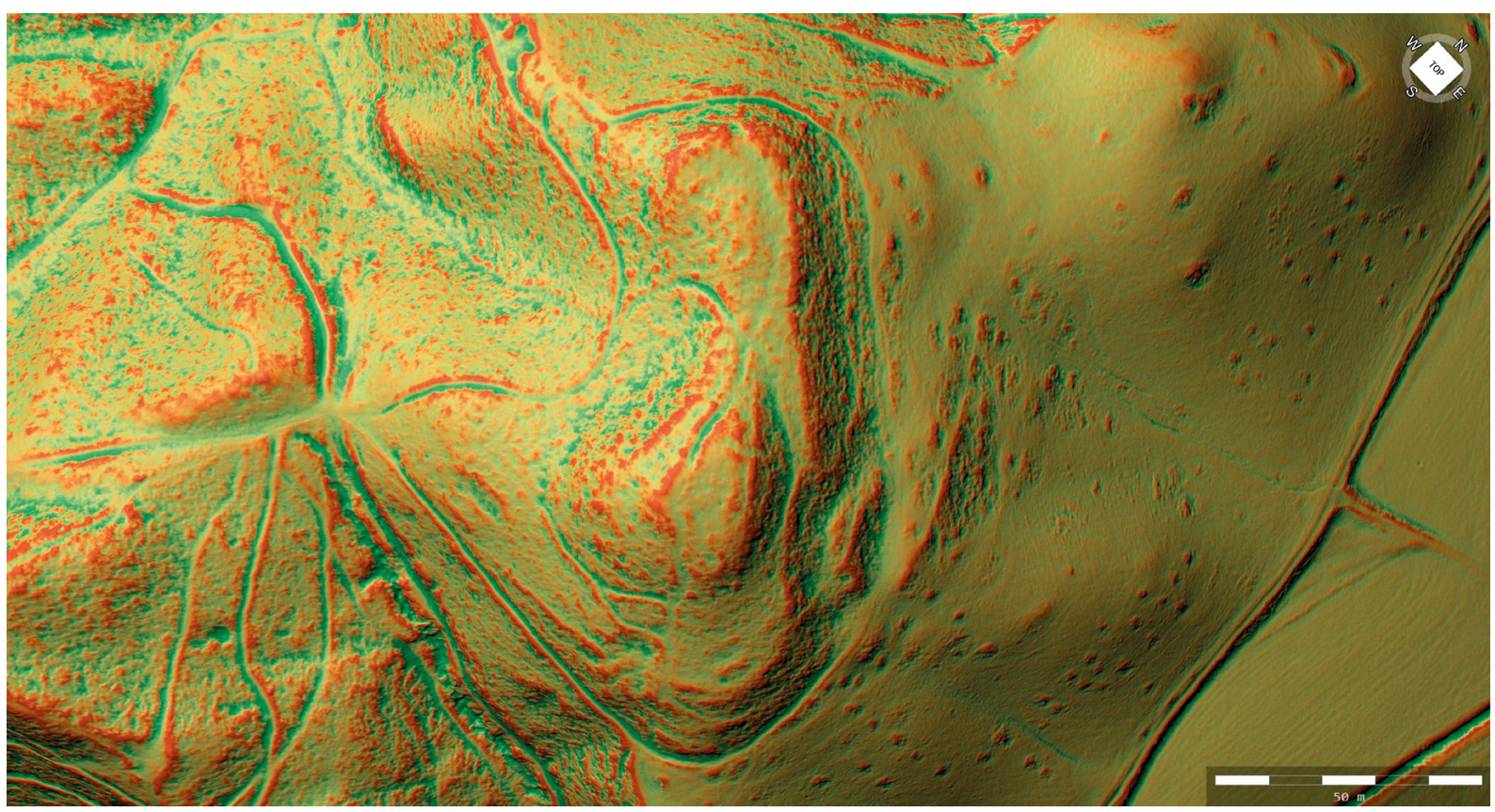

Figura 18. Imagem derivada dos dados LiDAR do sítio do Alto da Águia, provável atalaia defensiva dos Chões de Alpompé

Figure 18. Image derived from the LiDAR data of the Alto da Águia, likely a defensive watchtower of Chões de Alpompé

Independentemente da planta ou da dimensão dos recintos militares, a nível da sua organização interna todos se configuram de forma relativamente similar, o que é consequência direta das pautas fixas que se aplicam na castrametação romana, embora adaptando-se às condicionantes topográficas locais. Este modelo comum obedece à conveniência das tropas, que, assim, sabiam sempre a disposição interna do acampamento e qual era o espaço dos principais serviços e infraestruturas (Morillo Cerdán e Adroher Auroux, 20I4: 39I). Nos acampamentos, os dois principais arruamentos, a via Este-Oeste (via principalis) e a Norte-Sul (via praetoria), cruzavam-se em ângulo recto na área onde se implantava a sede do quartel-general, o Praetorium (Morillo Cerdán e Adroher Auroux, 20r4: 394), sendo usual situar as áreas ocupadas pelo forum e o quaestorium de ambos os lados do Praetorium (Dobson, 2008: 75).

Por último, importa referir que, numa elevação localizada a algumas centenas de metros a Norte de Chões de Alpompé, foi identificada uma expressiva quantidade de materiais arqueológicos do período romano republicano. Este sítio, denominado na cartografia como Alto da Águia (Zyszweski et alii, I968: 50), está rodeado de taludes de terra, e foi interpretado como uma atalaia que defenderia «[...] o acampamento principal do lado menos defensável.» (Zbyszweski et alii, 1968: 56). Durante os trabalhos arqueológicos efectuados em 2015 e 20I6, foi possível visitá-lo e constatar a validez desta proposta. A presença à superfície de materiais arqueológicos compatíveis com uma ocupação do século II-I a. C. é de sublinhar, destacando-se a presença de fragmentos de ânforas produzidas no vale do Guadalquivir, que apresentam morfologias centradas no século i a. C. A análise dos modelos derivados dos dados LiDAR permitiu constatar a existência de taludes defensivos em redor do topo da elevação (figura 18), cuja leitura se torna difícil dada a densidade de vegetação. Estas evidências não têm sido, em nosso entender, devidamente valorizadas e merecem ser investigadas em futuros trabalhos. Adiante-se que a posição de controlo que o Alto da Águia detém sobre um dos acessos ao planalto é clara, em particular na visibilidade uma área que permitia a travessia do rio Alviela.

\section{Em jeito de conclusão}

O rio Tejo é um dos mais extensos e navegáveis rios ibéricos, com cerca de r ooo km de extensão. Constitui, nas palavras de Jorge Gaspar (1970: 154), «a artéria 


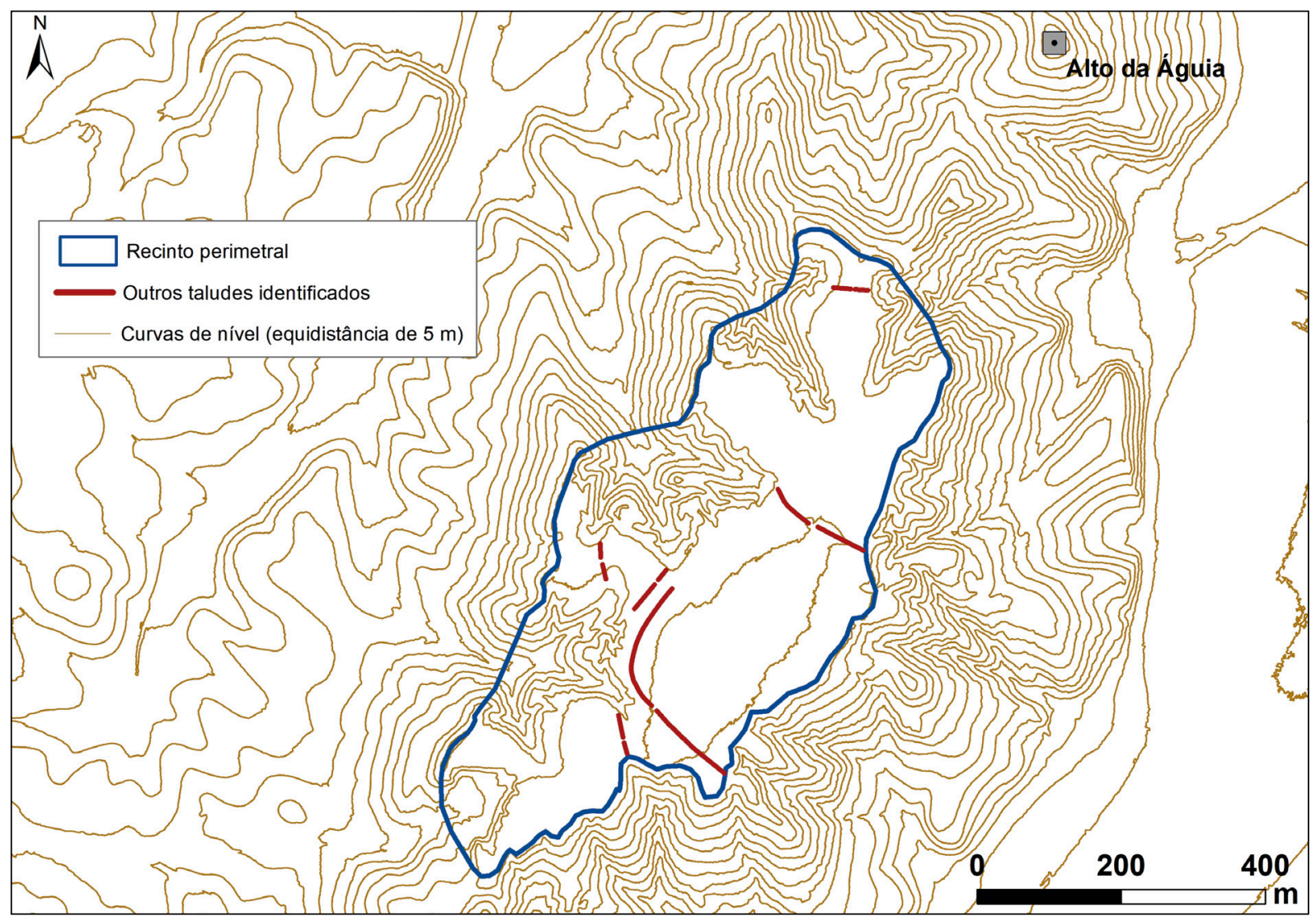

Figura 19. Novas evidências arqueológicas identificadas no planalto dos Chões de Alpompé relacionadas com a existência de dois possíveis recintos militares romanos

Figure 19. New archaeological evidence identified on the Chões de Alpompé plateau related to the existence of two possible Roman military enclosures

central da península», tendo desde a Idade do Bronze assumido uma importância preponderante na conectividade de bens e pessoas que se manteve ativa até ao advento do caminho-de-ferro, no século Xix (Vilaça e Arruda, 2004; Arruda 20I7; Vilaça e Cardoso, 2017).

Apesar da sua inegável relevância na estruturação do território e nas dinâmicas estratégicas de circulação entre a fachada atlântica e o interior do território peninsular, o seu papel como eixo da conquista romana tem sido de alguma forma relegado para segundo plano (Fabião, 20I4).

A particular implantação da foz do Tejo na fachada atlântica, associado às suas favoráveis condições naturais, fizeram com que este se constituísse num ponto incontornável de apoio à navegação. Consciente da relevância dos rios no processo de expansão romana, o autor grego Estrabão, na sua Geografia, descreve com algum detalhe os principais rios ibéricos, detendo-se na descrição da costa ocidental e setentrional da Ibéria, no Tejo:
O Tejo tem de embocadura uma extensão de vinte estádios e uma grande profundidade, de modo que pode ser subido por cargueiros com capacidade para dez mil ânforas. Quando as marés têm lugar, forma dois estuários nas planícies que se situam para o interior, de modo que se estende como um mar por cento e cinquenta estádios e torna a planície navegável [...] (Estrabão, III, 3.I) (Deserto e Pereira, 2016: 59).

De acordo com o geógrafo de Amásia, o efeito das marés para montante fazia-se sentir até ao porto de Morón (Chões de Alpompé, Santarém), considerado o último «porto de mar». Daqui subiam o rio em barcos de menor calado até ao interior da península: «[...] com as navegações fáceis até uma distância considerável, inclusive para grandes embarcações, embora o resto do percurso, apenas para barcos de rio [...]» (Estrabão, III, 3.I) (Deserto e Pereira, 20r6: 59). 
É precisamente a ampla navegabilidade e o acesso direto de navios de mar, aproveitando a força das marés no fundo do estuário, que possibilitou a posição estratégica do ponto de vista militar na fase de conquista da área em torno de Scallabis. E esse conhecimento do território, que se encontra plasmado na obra de Estrabão (Deserto e Pereira, 20I6), certamente chegou aos estrategas militares que planearam a campanha de Bruto.

Face às suas excelentes condições de navegabilidade, manifestas riquezas auríferas e recursos agropecuários, o vale do Tejo foi, desde cedo, procurado por comunidades exógenas que aqui se estabeleceram e interagiram com as populações indígenas.

No contexto pós-morte de Viriato, ocorreu a primeira grande ofensiva militar romana no extremo ocidental da Península Ibérica, campanha que teve assim como intuito "pacificar», de forma exemplar, a região onde estava a génese da anterior rebelião. Desencadeou-se em torno a ${ }_{3} 8$ a. C., e foi liderada pelo general Décimo Júnio Bruto.

A primeira referência direta à entrada do vale do Tejo na esfera de Roma é de Estrabão (III, 3.I), através do qual sabemos que, em 138 a. C., o novo governador da província romana da Ulterior, utilizou o vale do Tejo como eixo principal da sua campanha militar dirigida para o Noroeste Peninsular (Deserto e Pereira, 2016: 59-60). Na área tagana, usou Móron, no fundo do estuário, a cerca de $90 \mathrm{~km}$ da entrada do rio, como base de operações, e Olisipo, junto à foz, como cidade de retaguarda, controlando a entrada do rio, mantendo livre a navegação e assegurando o abastecimento aos exércitos (Deserto e Pereira, 2016: 59-60).
As novas evidências sobre Chões de Alpompé, obtidas pelo cruzamento dos dados de deteção remota com os das intervenções arqueológicas realizadas em 2015 e 20r8, e que aqui apresentámos, permitiram propor a existência de pelo menos dois recintos militares romanos: um maior e mais irregular que circundava todo o planalto e que muito provavelmente se poderá associar com a campanha de Bruto; e outro menor e mais regular que possivelmente se poderá relacionar com o conflito Sertoriano, hipótese esta que carece ainda de validação arqueológica (figura Ig).

\section{Agradecimentos}

A aquisição e processamento inicial dos dados LiDAR para efeitos de investigação em sismologia e tectónica activa no vale do Tejo foi realizada no âmbito dos projetos FINDER (PTDC/CTE-GIX/II3866/2009) e SHARPE (IF/or56I/20I4/CPI2I4/CTooo6) financiados pela Fundação para a Ciência e Tecnologia (FCT). Estes projetos foram liderados pela investigadora Susana Vilanova do Centro de Recursos Naturais e Ambiente (CERENA) do Instituto Superior Técnico (IST), a quem agradecemos imenso a disponibilização dos dados LiDAR para efeitos de investigação arqueológica.

Este trabalho contou com o apoio do projeto de investigação pós-doutoral de JF Finisterrae: Negotiating and contesting marginal landscapes on the Western fringes of the Roman Empire financiado no âmbito do European Union's Horizon 2020 research and innovation programme através de uma Marie Sktodowska-Curie Individual Fellowship (grant agreement 794048). 
Bibliografia

Alapont Martín,L.,Calvo Gálvez,M.e Ribera i Lacomba, A. (20I0): La destrucción de Valentia por Pompeyo. Quaderns de Difusió Arqueològica, 6. Valencia.

Alarcão, J. (1983): Portugal Romano. Editorial Verbo ( $3 \cdot{ }^{\mathrm{a}}$ edição). Lisboa.

Alarcão, J. (2002): “Scallabis e o seu território". Em A.M. Arruda, C. Viegas e M.J. de Almeida (eds.): De Scallabis a Santarém. Lisboa: 37-46.

Arruda, A.M. (20I7): "A Idade do Ferro Orientalizante no Estuário do Tejo: as duas margens do mesmo rio". Em S. Celestino Pérez e E. Rodríguez González (eds.): Territórios comparados: los valles del Guadalquivir, el Guadiana y el Tajo en época tartésica. Madrid: 283-294.

Arruda, A., Pereira, C., Sousa, E., Pimenta, J., Detry, C. e Gomes, J. (2018): "Chões de Alpompé (Vale de Figueira, Santarém): lendas e narrativas”. SPAL, 27(2): 20I-227.https://doi.org/IO.I2795/spal.20I8i27.2O

Bennett, R.,Welham, K., Hill, R.A.e Ford, A. (2OI2): "A comparison of visualization techniques for models created from airborne laser scanned data". Archaeological Prospection, 19: 4I-48. https:// doi.org/Io.IOO2/arp.I4I4

Blanco-Rotea, R., Costa-García,J.M., Fonte, J., Gago Mariño, M. e Gonçalves, J.A. (20I6): “A Modern Age redoubt in a possible Roman camp. The relationship between two defensive models in Campos (Vila Nova de Cerveira, Minho Valley, Portugal)". Journal of Archaeological Science: Reports, I0: 293-308. https://doi.org/ro.IoI6/j.jasrep.20I6.Io.oo8

Blázquez Martínez,J. (I999): “Campamentos romanos en la meseta hispana de época romano republicana”. Em M. Almagro Gorbea,J.M. Blázquez Martínez, M. Reddé, J. González Echegaray, J. Ramírez Sádaba e E. Peralta Labrador (coords.): Las guerras cántabras, Santander: 65-II8.

Calo Lourido, F. (1994): A Plástica da Cultura Castrexa Galaico-Portuguesa, 2 vols. Fundación Pedro Barrié de la Maza. A Coruña.

Canora, C., Vilanova, S., Besana-Ostmana, G., Carvalho, J., Heleno, S. e Fonseca, J. (2015): “The Eastern Lower Tagus Valley Fault Zone in central Portugal: active faulting in a low-deformation region within a major river environment". Tectonophysics, 660: II7-I3I. http://dx.doi.org/ro.IoI6/j.tecto.20I5.08.026
Challis, K., Forlin, P. e Kincey, M. (20II): "A generic toolkit for the visualization of archaeological features on airborne LiDAR elevation data". Archaeological Prospection, 18: 279-289. https://doi. org/IO.1002/arp.42I

Deserto, J. e Pereira, S. (2016): Estrabão, Geografia. Livro III: introdução, tradução do grego e notas. Universidade de Coimbra. Coimbra. https://doi. org/Io.I4I95/978-989-26-I226-3

Devereux, B.J., Amable, G.S. e Crow, P. (2008): “Visualisation of LiDAR terrain models for archaeological feature detection". Antiquity, 82: 470-479. https://doi.org/Io.IoI7/Sooo3598Xooo96952

Diogo, A. (I982): "A propósito de Moron. Estudo de alguns documentos provenientes dos Chões de Alpompé (Santarém)". Clio, 4: I47-I54

Diogo A. e Trindade, L. (1993-94): "Materiais provenientes dos Chões de Alpompé (Santarém)". Conimbriga, 32-33: 263-28I.

Dobson, M. (2008): The Army of the Roman Republic. The Second Century BC, Polybius and the Camps at Numantia, Spain. Oxbow Books. Oxford.

Doneus, M. (2013): "Openness as visualization technique for interpretative mapping of airborne LiDAR derived digital terrain models". Remote Sensing, 5: 6427-6442. https://doi.org/ro.339o/ rs5126427

Fabião, C. (2002): "Chões de Alpompé". Em A.M. Arruda, C. Viegas e M.J. de Almeida (eds.): De Scallabis a Santarém. Lisboa: I49-I52.

Fabião, C. (2004): "Arqueología Militar romana da Lusitania: textos e evidencias materiais". Em C. Pérez-González y E. Illarregui (coords.): Actas Arqueología Militar Romana en Europa. Salamanca: $53^{-} 73$.

Fabião, C. (2007): "El ejército romano en Portugal". El ejército romano en Hispania. Guia Arqueológica. León: II3-I34

Fabião, C. (20I4): "Por este rio acima: conquista e implantação romana no ocidente da península ibérica". Cira Arqueologia, 3: 9-24.

Fabião, C., Pereira, T.R. e Pimenta, J. (2015): "Coleção de metais do sítio arqueológico dos Chões de Alpompé - Santarém”. Cira Arqueologia, 4: IIO-I5O. 
Ferreira, C., Catarino, J. e Pinho, L. (1993): "Chões de Alpompé. Síntese cultural”. Revista ESES. Escola Superior de Educaşão de Santarém, 3 de Janeiro de 1993: 55-63.

Fonte,J. e Costa-García,J.M. (20r6): "Alto da Cerca (Valpaços, Portugal): um assentamento militar romano na Serra da Padrela e sua relação com o distrito mineiro de Tresminas". Estudos do Quaternário, I4: 39-58.

Fonte, J., Lima, A., Matías, R., Leal, S. e Gonçalves, J.A. (2017): "Novas evidências de mineração aurífera e estanhífera de época Romana no alto vale do Tâmega (Montalegre e Boticas, Norte de Portugal)". Estudos do Quaternário, I7: 45-55.

Foroutan, M., Vilanova, S., Heleno, S., Pinto, L., Sajedi Far, A., Falcão-Flor A., Canora, C., Pina, P., Vieira, G. e Fonseca, J. (2016): “New evidence for large earthquakes in mainland Portugal: paleoseismology of the Lower Tagus Valley fault". $35^{\text {th }}$ General Assembly of the European Seismological Commission, Trieste.

Garcia, J. (1977): "Em torno de Scallabis". Santarém. A Cidade e os Homens. Santarém: 65-77.

García Vargas, E., Almeida, R.R. e González Cesteiros, H. (20II): "Los tipos anfóricos del Guadalquivir en el marco de los envases hispanos del siglo i a.C. Un universo heterogéneo entre la imitación y la estandarización”. SPAL, 20: I85-283.

García Merino, C. (1996): "Un nuevo campamento romano en la cuenca del Duero: el recinto campamental de Uxama (Soria)". Archivo Español de Arqueología, 69: 269-274.

García Merino, C. (2007): "Asentamientos militares de época romana en Hispania: una guía arqueológica”. Em A. Morillo Cerdán (ed.): El ejército romano en Hispania. León: 324-325.

Girão, A. de A. e Oleiro,J.M.B. (I953): "Geografia e campos fortificados romanos". Boletim do Centro de Estudos Geográficos, I(6-7): 73-80.

Gómez Pantoja, J. e Morales Hernández, F. (2002): "Sertorio en Numancia: una nota sobre los campamentos de la Gran Atalaya”. Em A. Morillo Cerdán (coord.): Arqueología militar romana en Hispania. Madrid: 303-310.
Gonçalves, J.A. (2016): "Automatic orientation and mosaicking of archived aerial photography using structure from motion". The International Archives of the Photogrammetry, Remote Sensing and Spatial Information Sciences, XL-3/W4: I23-I26.https://doi. org/ro.5194/isprs-archives-XL-3-W4-I23-20I6

González-Ruibal, A. (2004): "Artistic Expression and Material Culture in Celtic Gallaecia”.e-Keltoi:Journal of Interdisciplinary Celtic Studies, vol. 6, Article 3. https://dc.uwm.edu/ekeltoi/vol6/isst/3 González-Ruibal, A. (2006-o7): Galaicos. Poder y comunidad en el Noroeste de la Peninsula Ibérica (I200 a.C.-50 d.C.). Brigantium I8-I9. Museu Arqueolóxico e Histórico da Coruña. A Coruña.

Guyot, A., Hubert-Moy, L. e Lorho, T. (2018): “Detecting Neolithic burial mounds from LiDAR-derived elevation data using a multi-scale approach and machine learning techniques". Remote Sensing, IO(2): 225. https://doi.org/IO.339o/rsioo20225

Harnung, S. (20I5): "Ein spätrepublikanisches militärlager bei hermeskeil (Lkr. Trier-Saarburg)". Archäologisches Korrespondenzblatt, 42: 205-224.

Hesse, R. (2010): "LiDAR-derived Local Relief Models - A new tool for archaeological prospection". Archaeological Prospection, $17: 67-72$. https:// doi.org/ı.I0o2/arp.374

Kalb, P. e Höck, M. (1982): "Alto do Castelo, Alpiarça. Distrikt Santarém. Vorberich über die Grabungen 198I". Madrider Mitteilungen, 23: I45-15I.

Kalb, P. e Höck, M. (1983): "El Alto do Castelo, Alpiarça (Distrito de Santarèm, Portugal) ¿Un campamento romano?". Actas do XVI Congreso Nacional de Arqueologia (Murcia-Cartagena, 1982). Zaragoza. 829-832.

Kalb, P.e Höck, M. (1986): “Alto do Castelo, Alpiarça ein römisches Lager in Portugal? Studien zu Militärgrenzen Roms III", I3 Internationalen Limeskongress (Aalen, 1983), Stutgart.

Kalb, F. e Höck, M. (1988): "Moron”. Conimbriga, 27: I89-20I

Kokalj, Ž. e Somrak, M. (2019): Why Not a Single Image? Combining Visualizations to Facilitate Fieldwork and On-Screen Mapping. Remote Sensing, Ir: 747. https://doi.org/I0.3390/rsio70747

Leão, D.N. de (1975): Crónicas dos Reis de Portugal/reformadas por Duarte Nunes de Leão. Lelloe Irmão. Porto. 
Leitão, J. (20I4): "Primeiro ensaio de SIG aplicado ao acampamento romano de Antanhol (Coimbra) 2". Em M. Osório (coord.): Experiências $S I G$ na Arqueologia portuguesa. Coimbra: 78-95.

Luik, M. (2007): "Renieblas. Asentamientos militares de época romana en Hispania", Em A. Morillo Cerdán (ed.): El ejército romano en Hispania. Una Guia Arqueológica, León: 286-293.

Luo, L., Wang, X., Guo, H., Lasaponara, R., Zong, X., Masini, N., Wang, G., Shi, P., Khatteli, H., Chen, F., Tariq, S., Shao, J., Bachagha, N., Yang, R. e Yao, Y. (2019): "Airborne and spaceborne remote sensing for archaeological and cultural heritage applications: A review of the century (1907-2017)". Remote Sensing of Environment, 232: III280. https://doi.org/ro.Ior6/j.rse.20I9.III280

Mantas, V. (1986): "Arqueologia urbana e fotografia aérea: contributo para o estudo do urbanismo antigo de Santarém, Évora e Faro". Trabalhos de Arqueologia, 3: 13-26.

Matias, A. (Coord.) (2018): Santarém Carta Arqueológica Municipal. Museu Municipal de Santarém. Santarém.

Morales Hernández, F. (2000): "Una reinterpretación de la circunvalación escipiónica de Numancia”. Revista d'Arqueología de Ponent, 10: 227-24I.

Morillo Cerdán, A. (2003): "Los establecimientos militares temporales: conquista y defensa del territorio en la Hispania republicana”. Em A. Morillo; F. Cadiou e D. Hourcade (eds.): Defensa y territorio en Hispania de los Escipiones a Augusto. León-Madrid: 4I-80.

Morillo Cerdán, A. (2008): “Criterios arqueológicos de identificación de los campamentos romanos en Hispania" Salduie, 8: 73-93.

Morillo Cerdán, A. e Adroher Auroux, A. (2014): "Modelos de Arquitectura Militar e implantación territorial de los campamentos republicanos en Hispania”. Em R. Mataloto; V.Mayoral Herrera e C. Roque (eds.): La Gestación de los paisajes rurales entre la Protohistoria y el Periodo Romano. Formas de Asentamiento y Procesos de Implantación (Reunión científica, Redondo-Alandroal, 24-25 Maio, 20I2). Anejos de AEspA, LXX. Madrid: 227-25I.
Morillo Cerdán, A. e Morales Hernández, F. (2016): "Campamentos romanos de la guerra de Numancia: La circunvalación Escipiónica”. Em M. Bendala Galán (ed.): Los Escipiones. Roma conquista Hispania. Alcalá de Henares: 275-298.

Nuñez Marcen, J. (1998): "La arquitectura pública de época romana en el País Vasco y sus áreas geográficas limítrofes. Una aproximación crítica”. Iberia, I: II5-I44.

Opitz, R. e Cowley, D. (eds.) (2013): Interpreting archaeological topography: airborne laser scanning, ${ }_{3} D$ data and ground observation. Oxbow Books. Oxford.

Orengo, H.A. e Petrie, C.A. (2018): "Multi-scale relief model (MSRM): A new algorithm for the visualization of subtle topographic change of variable size in digital elevation models". Earth Surface Processes and Landforms, 43: 1361-1369. https://doi.org/ro.I0o2/esp.43I7

Pereira, C. e Silva, R. (2020): Chóes de Alpompé, Vale de Figueira. Desmatação na área de proteção do sitio de Chôes de Alpompé Santarém. Relatório Final.

Pimenta, J. (2005): As ânforas romanas do Castelo de São Jorge (Lisboa). Instituto Português de Arqueologia. Lisboa.

Pimenta, J. e Arruda, A. (2014): "Novos dados para o estudo dos Chões de Alpompé - Santarém". Estudos Arqueológicos de Oeiras, 21: 375-392.

Pimenta, J., Henriques, E. e Mendes, H. (2012): O Acampamento romano de Alto dos Cacos. Associação de Defesa do património Histórico e Cultural do Concelho de Almeirim. Almeirim.

Pinheiro, M. (1988): "A construção dos caminhos-deferro e a encomenda de produtos industriais em Portugal (I855-90)". Análise Social, 24 (IOI-IO2): 745-767.

Redweik, P., Roque, D., Marques, A., Matildes, R. e Marques, F. (2010): "Triangulating the Past Recovering Portugal's Aerial Images Repository". Photogrammetric Engineering e Remote Sensing, 9: I007-IOI8.

https://doi.org/Io.I4358/ PERS.76.9.1007

Ribera i Lacomba, A. (1998): La fundació de Valencia. La ciutat a l'época romana republicana (Segles II-I a. de C.). Universidad de Valencia. Valencia. 
Ribera i Lacomba, A. (2002): "El papel militar de la fundación de Valentia (I38 a.n.e.): historia y arqueología”. Em A. Morillo Cerdán, F. Cadiou e D. Hourcade (coords.): Defensa y Territorio en Hispania de los Escipiones a Augusto (espacios urbanos y rurales y provinciales). Madrid: 363-39o.

Ruivo,J. (1999): "Moedas do acampamento romanorepublicano dos Chões de Alpompé (Santarém)". Em R. Centeno, M. García-Bellido e G. Mora (eds.): Rutas, Ciudades y Moneda en Hispania.Actas del II Encuentro Peninsular de Numismática Antigua (Porto, 1997). CSIC. Madrid: IoI-IIo.

Saa, M. (1956): As Grandes Vias da Lusitânia. O Itinerário de Antonino Pio. Sociedade Astória, I. Lisboa.

Sánchez-Lafuente Pérez, J. (1979): “Aportaciones al estudio del campamento romano de La Cerca (Aguilar de Anguita, Guadalajara)". Wad-alHayara, 6: 77-82.

Sevara, C. (2013): "Top secret topographies: recovering two and three-dimensional archaeological information from historic reconnaissance datasets using image-based modelling techniques". International Journal of Heritage in the Digital Era, 2: 395-418. https://doi.org/Io.I26o/2047-4970.2.3395
Sevara, C.; Verhoeven, G.; Doneus, M. e Draganits, E. (2018): "Surfaces from the Visual Past: Recovering High-Resolution Terrain Data from Historic Aerial Imagery for Multitemporal Landscape Analysis". Journal of Archaeological Method and Theory, 25: 6II-642. https://doi.org/Io.Ioo7/ sio8i6-or7-9348-9

Silva, A.C.F. da (2007): A Cultura Castreja do Noroeste de Portugal. Câmara Municipal de Paços de Ferreira. Paços de Ferreira.

Štular, B.; Kokalj, Ž.; Oštir, K. e Nuninger, L. (2OI2): "Visualization of lidar-derived relief models for detection of archaeological features". Journal of Archaeological Science, 39: 3354-3360. https://doi. org/Io.IoI6/j.jas.2012.05.029

Vilaça. R. e Arruda, A. (2004): "Ao longo do Tejo, do Bronze ao Ferro". Conimbriga, 43: II-45.

Vilaça. R. e Cardoso, J.L. (20I7): "O Tejo português durante o Bronze Final”. Em S. Celestino Peréz (ed.): Territórios comparados: los valles del Guadalquivir; el Guadiana y el Tajo en época tartésica. Anejos de AEsPA, LXXX, 3-4: 237-28r.

Zakšek, K., Oštir, K. e Kokalj, Ž. (20II): "Sky-view factor as a relief visualization technique". Remote Sensing, 3: 398-415.https://doi.org/Io.339o/rs3020398 Zbyszweski, G., Ferreira, O. da V. e Santos, C. (I968): "Acerca do campo fortificado de Chões de Alpompé (Santarém)". O Arqueólogo Português, 3-2: 49-57. 